NISTIR 8250

\title{
Calibration Procedures for Weights and Measures Laboratories
}

Georgia L. Harris (Editor)

This publication is available free of charge from:

https://doi.org/10.6028/NIST.IR.8250

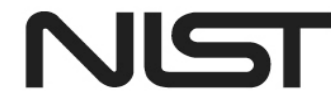

National Institute of Standards and Technology U.S. Department of Commerce 
NISTIR 8250

\title{
Calibration Procedures for Weights and Measures Laboratories
}

\author{
Georgia L. Harris (Editor) \\ Office of Weights and Measures \\ Physical Measurements Laboratory
}

This publication is available free of charge from:

https://doi.org/10.6028/NIST.IR.8250

May 2019

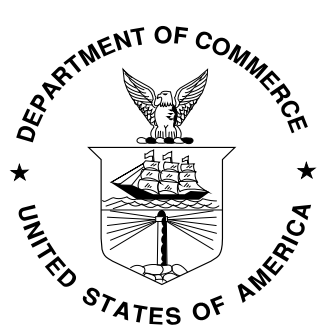

U.S. Department of Commerce Wilbur L. Ross, Jr., Secretary

National Institute of Standards and Technology Walter Copan, NIST Director and Undersecretary of Commerce for Standards and Technology 
Certain commercial entities, equipment, or materials may be identified in this document in order to describe an experimental procedure or concept adequately. Such identification is not intended to imply recommendation or endorsement by the National Institute of Standards and Technology, nor is it intended to imply that the entities, materials, or equipment are necessarily the best available for the purpose.

National Institute of Standards and Technology Interagency or Internal Report 8250

Natl. Inst. Stand. Technol. Interag. Intern. Rep. 8250, 83 pages (May 2019)

This publication is available free of charge from:

https://doi.org/10.6028/NIST.IR.8250 


\section{Preface}

This publication was compiled from procedures submitted by weights and measures laboratories that have been validated and used by the laboratory to perform calibrations in support of legal metrology. The Office of Weights and Measures has compiled this set of procedures with the intent to standardize the format and content, and to recognize nationally validated and adopted procedures.

Comments on this interim publication may be submitted to:

NIST Office of Weights and Measures

Mail Stop 2600, Gaithersburg, MD 20899.

\section{Acknowledgements}

Draft and sample procedures were submitted by the following weights and measures laboratories or Federal programs:

- Alaska Department of Transportation \& Public Facilities

- Arizona Metrology Laboratory

- California Department of Food and Agriculture, Division of Measurement Standards

- Colorado Department of Agriculture

- Maine Department of Agriculture, Conservation \& Forestry Div. Quality Assurance and Regulations

- Michigan Department of Agriculture

- Minnesota Metrology Laboratory - Division of Weights \& Measures

- State of New Jersey, Department of Law and Public Safety, Division of Consumer Affairs, Office of Weights and Measures

- New Mexico Department of Agriculture, Standards and Consumer Services

- New York Bureau of Weights and Measures

- North Carolina Department of Agriculture and Consumer Services

- Oklahoma Department of Agriculture, Bureau of Standards

- Oregon Department of Agriculture, Weights and Measures Program

- Pennsylvania Standards Lab

- Texas Department of Agriculture

- USDA Grain Inspection Packers and Stockyards Administration

The Table of Contents contains a supplemental itemized list of Standard Operating Procedures that are related to the current NISTIR set of procedures but which have been published in other publications or are still in interim draft form and have not been published:

- NBS Handbook 145, 1986, Handbook for the Quality Assurance of Metrological Measurements, by John K. Taylor, and Henry V. Oppermann which is out of print;

- NISTIR 6969, Selected Laboratory and Measurement Practices, and Procedures to Support Basic Mass Calibrations;

- NISTIR 5672, Advanced Mass Calibrations and Measurements Assurance Program for the State Calibration Laboratories; 
- $\quad$ NISTIR 7383, Selected Procedures for Volumetric Calibrations; and

- $\quad$ NISTIR 8028, 2014, Selected Laboratory and Measurement Practices and Procedures for Length Calibrations.

NOTE Regarding Units of Measure:

The commercial measurement system in the United States continues to use non-SI units for practical applications and manufacturers in this industry continue to use U.S. Customary dimensions. Since commercial applications in the United States use units other than SI or other accepted metric units, this document references common units in current use.

Disclaimer:

Certain commercial entities, equipment, or materials may be identified in this document in order to describe an experimental procedure or concept adequately. Such identification is not intended to imply recommendation or endorsement by the National Institute of Standards and Technology, nor is it intended to imply that the entities, materials, or equipment are necessarily the best available for the purpose. 


\begin{abstract}
This publication contains standard operating procedures for calibrations that were not previously published in other NIST Office of Weights and Measures publications and are included here in support of weights and measures laboratory program requirements to ensure suitable metrological traceability, and uncertainty in calibrations. The current and proposed procedures cover a variety of measurement parameters including: time and frequency, electricity, mass, force, volume, dimensional, thermodynamic, pressure, liquid and solid density, and magnetism in mass standards.
\end{abstract}

\title{
Key words
}

Calibration procedures; metrological traceability; standard operating procedures, weights and measures. 
This page is intentionally blank. 
Preface

Good Laboratory Practices

14 Method Validation

GLP 14-1

15 Software Quality Assurance

GLP 15-1

Standard Operating Procedures for Time and Frequency

22 Calibration of Traffic Speed Guns and Tuning Forks

SOP 22-1

24 Calibration of Field Standard Stopwatches

SOP 24-1

Standard Operating Procedures for Mass and Force

27 Calibration of Railroad Test Cars (Mass)

SOP 27-1

Standard Operating Procedures for Thermodynamic and Pressure

49 Calibration of Environmental Monitoring Standards by Direct

SOP 49-1 Comparison

Standard Operating Procedures for Density and Magnetism

52 Verification and Adjustment of Digital Conductivity Meter and

SOP 52-1 Measuring Water Conductivity 
Procedure Numbers by Number in NISTIR Publications (as noted)

\begin{tabular}{|c|c|c|}
\hline $\begin{array}{l}\text { SOP } \\
\text { No. }\end{array}$ & Title & NISTIR \\
\hline 1 & Preparation of Calibration Certificates & 6969 \\
\hline 2 & Applying Air Buoyancy Corrections & 6969 \\
\hline 3 & $\begin{array}{l}\text { Weighing by Double Substitution Using an Equal-Arm Balance (Handbook 145, } \\
1986 \text { Archive) }\end{array}$ & OOP \\
\hline 4 & Weighing by Double Substitution & 6969 \\
\hline 5 & Using a 3-1 Weighing Design & 5672 \\
\hline 6 & Weighing By Transposition (Handbook 145, 1986, Archive) & OOP \\
\hline 7 & $\begin{array}{l}\text { Weighing by Single Substitution Using a Single Pan Mechanical Balance, a Full } \\
\text { Electronic Balance, or a Balance with Digital Indications and Built in Weights }\end{array}$ & 6969 \\
\hline 8 & Medium Accuracy Calibrations of Mass Standards by Modified Substitution & 6969 \\
\hline 9 & Control Charts for Calibration of Mass Standards & 6969 \\
\hline 10 & Calibration of Rigid Rules & 8028 \\
\hline 11 & Calibration of Metal Tapes, Bench Method & 8028 \\
\hline 12 & Calibration of Steel Tapes, Tape-to-Tape Method & 8028 \\
\hline 13 & Calibration of Volumetric Ware, Gravimetric Method (2006 Archive) & 7383 \\
\hline 14 & Gravimetric Calibration of Volumetric Ware Using an Electronic Balance & 7383 \\
\hline 15 & $\begin{array}{l}\text { Calibration of Intermediate and Large Volume Standards Gravimetric Method } \\
\text { Using an Equal-Arm Balance (2006 Archive) }\end{array}$ & 7383 \\
\hline 16 & Calibration of Measuring Flasks, Volume Transfer Method (2017 Archive) & 7383 \\
\hline 17 & Control Charts of Laboratory Owned Check Standards & 7383 \\
\hline 18 & $\begin{array}{l}\text { Calibration of Graduated Neck-Type Metal Volumetric Field Standards, } \\
\text { Volumetric Transfer Method }\end{array}$ & 7383 \\
\hline 19 & Calibration of Large Neck-Type Metal Provers, Volume Transfer Method & 7383 \\
\hline 20 & Standard Deviation and Range Charts & 7383 \\
\hline 21 & Calibration of LPG Provers & 7383 \\
\hline 22 & Calibration of Traffic Speed Guns and Tuning Forks & 8250 \\
\hline 23 & Calibrations of PI Tapes Bench Method & 8028 \\
\hline 24 & Calibration of Field Standard Stopwatches & 8250 \\
\hline 26 & Gravimetric Calibration of Dynamic Volumetric Systems used as Standards & 7383 \\
\hline 27 & Calibration of Railroad Test Cars (Mass) & 8250 \\
\hline 28 & Using Advanced Weighing Designs & 5672 \\
\hline 29 & Assignment of Uncertainty & 6969 \\
\hline 30 & Process Measurement Assurance Program & 6969 \\
\hline 31 & Scale Plate Calibration for Volumetric Field Standards & 7383 \\
\hline 32 & Calibration of Watt Hour Meters & Draft \\
\hline 33 & Calibration of Weights Carts & 6969 \\
\hline 34 & $\begin{array}{l}\text { Selection and Use of Sensitivity Weights and Tare Weights in Weighing } \\
\text { Procedures }\end{array}$ & 6969 \\
\hline 35 & Calibration of Test Chains by Substitution & Draft \\
\hline 36 & Calibration of Wheelload Weighers (Proving Rings and Load Cells) & Draft \\
\hline 37 & Calibration of Force Sensors & Draft \\
\hline 38 & Calibration or Testing of Lottery Balls by Mass (and Dimension) & Draft \\
\hline 39 & Calibration of Load Cells & Draft \\
\hline 40 & Calibration of Berry Baskets by Gravimetric Methods & Draft \\
\hline
\end{tabular}




\begin{tabular}{|c|l|c|}
\hline $\begin{array}{c}\text { SOP } \\
\text { No. }\end{array}$ & \multicolumn{1}{|c|}{ Title } & NISTIR \\
\hline \hline 41 & $\begin{array}{l}\text { Calibration of Boxes Used for Package Testing by Dimensional } \\
\text { Measurements }\end{array}$ & Draft \\
\hline 42 & $\begin{array}{l}\text { Field Standard Meter Calibration by Gravimetric Calibration OR Volume } \\
\text { Transfer }\end{array}$ & Draft \\
\hline 43 & Calibration and Testing of Lottery Balls by Mass and Dimension & Draft \\
\hline 44 & Calibration of Microscope Reticle for Length Calibrations & Draft \\
\hline 45 & Linear Shellfish Gages & Draft \\
\hline 46 & Calibration of Field Standard Thermometers & Draft \\
\hline 47 & Calibration of Liquid-in-Glass Thermometers & Draft \\
\hline 48 & Calibration of PRT and SPRT and Digital Thermometers & Draft \\
\hline 49 & Calibration of Environmental Monitoring Standards by Direct Comparison & 8250 \\
\hline 50 & Calibration of Hydrometers & Draft \\
\hline 51 & Evaluation of Magnetism in Mass Standards & Draft \\
\hline 52 & $\begin{array}{l}\text { Verification and Adjustment of Digital Conductivity Meter and Measuring } \\
\text { Water Conductivity }\end{array}$ & 8250 \\
\hline 53 & Testing Density of Mass Standards & Draft \\
\hline
\end{tabular}

OOP: Out of Print

Draft: Publication created as draft and used by laboratories since 1990s. Not published in this interim publication. Proposed for future publication when standardization and technical reviews are completed. 
This page is intentionally blank. 
Good Laboratory Practices 
This page is intentionally blank. 


\section{GLP 14}

\section{Good Laboratory Practice \\ for}

Procedure for Method Validation

\section{Introduction}

This is the metrology laboratory policy and procedure for developing and validating test or calibration methods when no international or national procedures are available, when deviating from standardized methods, or when no standard procedures are available.

\section{$2 \quad$ Purpose}

The Metrology Laboratory follows this procedure to ensure that all laboratory methods selected, modified, or developed for tests and calibrations are appropriate for the intended use, properly documented, validated, accepted by laboratory management, and agreed upon by the client. Customers of the Laboratory expect a given service to provide acceptable measurement results when they request a test or calibration. The laboratory must evaluate each method to ensure that it has qualified and competent staff, suitable facilities, equipment, and standards with acceptable metrological traceability to perform the test or calibration.

3 Responsibility

3.1 The Laboratory Supervisor or Quality Manager ensures the following, in consultation with the laboratory staff as needed:

3.1.1 development of methods is a planned activity and assigned to qualified staff with appropriate resources;

3.1.2 for larger projects, plans are updated as progress is made and effectively communicated to all personnel; and

3.1.3 ensures the certificate for the test or calibration is compliant with standard requirements and customer needs.

3.2 The Technical Manager reviews the documented procedure, data, and analysis, and recommends final acceptance to the Laboratory Manager or Quality Manager based on the suitability of the procedure and acceptability of observed analysis of measurement results.

3.3 The Laboratory Supervisor or Quality Manager is responsible for final acceptance of new calibration methods, training staff on the new procedure, and for consistent implementation. 
Operations

4.1 If the laboratory does not have an appropriate method for a calibration or test, or the test or calibration requires deviation to meet the needs of the customer, the Technical Manager is notified and this procedure is implemented.

4.2 When determining whether to proceed in developing new test or calibration method to meet the needs of a customer, the Laboratory Supervisor or Quality Manager and Technical Manager consider at least the following factors:

4.2.1 availability of alternative procedures (national or international standards);

4.2.2 resources of the laboratory and staffing (time, efficiency); and

4.2.3 likely future demand for the service.

4.3 The staff conducting the Contract Review for the calibration or test must obtain a clear specification of the customer requirements and the purpose of the test or calibration including any tolerances or maximum uncertainties that are required for the item/sample end usage (to ensure that the measurement results will be fit for purpose).

4.4 New methods must be developed prior to performing the tests or calibrations and contain the following information:

\subsubsection{Appropriate identification (title);}

4.4.2 Scope or range of test;

4.4.3 Description of the type of item to be tested or calibrated;

4.4.4 Parameters or quantities and ranges to be determined;

4.4.5 Apparatus and equipment, including technical performance requirements;

4.4.6 Reference standards and reference materials required;

4.4.7 Environmental conditions required, and any stabilization period needed;

4.4.8 Description of the procedure, including any special items as noted in this list:

4.4.8.1 Affixing of identification marks, handling, transporting, storing and preparation of items,

4.4.8.2 Checks to be made before the work is started,

4.4.8.3 Checks that the equipment is working properly and, where required, calibration and adjustment of the equipment before each use, 
4.4.8.4 Method of recording the observations, data to be recorded, data reduction, method of analysis, and presentation of results, and

4.4.8.5 Safety measures to be observed;

4.4.9 Criteria and/or requirements for approval/rejection where applicable;

4.4.10 Data to be recorded and method of analysis and presentation; and

4.4.11 Uncertainty or the procedure for estimating uncertainty.

$5 \quad$ Method Validation

5.1 Non-standardized methods, which include all laboratory developed methods, standardized methods modified beyond their intended scope and amplifications and modifications of standardized methods, are validated by:

5.1.1 Examination to ensure completeness and compliance with requirements for essential components of metrological traceability; and

5.1.2 Analysis of objective evidence to ensure the requirements for a specific intended purpose are fulfilled prior to use.

5.2 Validation methods are to be as extensive as necessary to meet the needs of their intended application. Adequate measurement data is obtained to ensure statistical validity of the evaluated results. The accuracy and uncertainty of test or calibration results shall be assessed for the intended use, and shall be relevant to the client's needs.

5.3 Validation procedures and results are recorded, with a statement concerning the appropriateness of the new method as it pertains to the intended use.

5.4 Validation techniques include one or a combination of the following:

5.4.1 Calibration/verification and evaluation of bias and precision using calibrated working standards;

5.4.2 Comparison of results achieved with other standardized methods;

5.4.3 Method evaluation through variations of controlled parameters (e.g., one variable at a time) to determine robustness;

5.4.4 Inter-laboratory comparisons when practical;

5.4.5 Systematic assessment of factors influencing the results; and

5.4.6 Evaluation of the uncertainty of results based on scientific understanding of the theoretical principles associated with the method and practical experience. 
5.5 When changes are made in the validated non-standardized procedures, the influence of such changes must be documented and, if appropriate, a new validation process carried out.

5.6 The following types of assessments, with data and statistical analysis are examples that may be used to assess the measurement results (See Appendix A form):

5.6.1 Inspection and technical assessment of the essential elements of metrological traceability to ensure presence and adequacy (technical review may include representatives from other laboratories, working groups, technical experts, and assessors):

5.6.1.1 Reference to the international system of units (SI);

5.6.1.2 Unbroken chain of calibrations to national and/or international standards;

5.6.1.3 Suitable and up to date calibration intervals for standards used in the procedure;

5.6.1.4 Documented procedure (reviewed to ensure completeness against the list of items in Section 4.d.);

5.6.1.5 Documented measurement uncertainty (as noted in Section 4.d.v.);

5.6.1.6 Demonstrated technical competence;

5.6.1.7 Adequate measurement assurance approach and supporting data.

5.6.2 Accuracy or Limits to Bias may use data obtained from internal testing and/or interlaboratory comparisons: t-test, normalized error $\left(E_{n}\right)$, absolute or relative bias versus required tolerance limits;

5.6.3 Precision: standard deviation, normalized precision $\left(\mathrm{P}_{\mathrm{n}}\right)$, F-test, comparison to required uncertainties (fit for purpose and meeting needs of the customer)

5.6.4 Repeatability: assessment of results over time and by different operators following the procedure as documented; and

5.6.5 Reproducibility: assessment of data from other laboratories following the procedure.

6 Records. (See Appendix A for summary of validation records to be supplemented with appropriate data, analysis, and evaluation records.)

6.1 Laboratory records shall be retained for all aspects of the procedure validation for as long as the procedure remains in valid use, including but not limited to:

6.1.1 Validation procedure (and version) that is used; 


\subsubsection{Any applicable specifications and/or tolerances;}

6.1.3 Evaluation of performance characteristics and summaries;

6.1.4 Observed data and measurement results;

6.1.5 Approval for use by the customer; and

6.1.6 A statement that the method is valid and suitable for its intended use.

7 Implementation

7.1 A laboratory developed test or calibration method is validated, reviewed by the Technical Manager, reviewed by the Quality Manager, and approved by the Laboratory Supervisor.

7.2 The method is documented and formatted into a written Standard Operating Procedure (SOP) document and assigned an identification number. The new SOP will be added to the laboratory Master List.

7.3 Staff are trained and competency is confirmed.

7.4 All laboratory method validation documentation is kept on file in the laboratory and maintained according to the Quality Management System.

8 Acknowledgment and Validation

This publication was presented as part of a collection of draft Standard Administrative Procedures in 1996 and has been adopted by many weights and measures laboratories in some form since that time. The procedure has also been used in NIST seminars covering calibration procedure validation as a part of compliance with ISO/IEC 17025. 


\section{Appendix A}

\section{Evaluation Form for Method Validation Review}

Procedure Evaluated:

Evaluation Conducted by:

\begin{tabular}{|c|c|}
\hline $\begin{array}{ll}\text { Method Evaluation } \\
\end{array}$ & Observations \\
\hline $\begin{array}{l}\text { Procedure is complete and contains: } \\
\square \quad \text { appropriate identification (title); } \\
\square \quad \text { scope or range of test; } \\
\square \quad \text { description of the type of item to be tested or calibrated; } \\
\square \quad \text { parameters or quantities and ranges to be determined; } \\
\square \quad \text { apparatus and equipment, including technical performance } \\
\text { requirements; } \\
\square \quad \text { reference standards and reference materials required; } \\
\square \quad \text { environmental conditions required and any stabilization } \\
\text { period needed; } \\
\square \quad \text { description of the procedure, including any special items as } \\
\text { noted in this list: } \\
\square \text { affixing of identification marks, handling, transporting, } \\
\text { storing and preparation of items, } \\
\square \text { checks to be made before the work is started, } \\
\square \text { checks that the equipment is working properly and, } \\
\text { where required, calibration and adjustment of the } \\
\quad \text { equipment before each use, } \\
\square \text { the method of recording the observations, data to be } \\
\text { recorded, data reduction, method of analysis, and } \\
\text { presentation of results, and } \\
\square \text { any safety measures to be observed; } \\
\square \quad \text { criteria and/or requirements for approval/rejection where } \\
\text { applicable; } \\
\text { data to be recorded and method of analysis and } \\
\text { presentation; and } \\
\text { the uncertainty or the procedure for estimating uncertainty. }\end{array}$ & \\
\hline $\begin{array}{l}\text { Essential Elements of Traceability are Defined (5.f, i) See GMP } \\
13 .\end{array}$ & \\
\hline $\begin{array}{l}\text { Realization of SI Units. The primary national, international, or } \\
\text { intrinsic standards must be primary standards for the realization } \\
\text { of the International System of Units (SI); }\end{array}$ & \\
\hline $\begin{array}{l}\text { Unbroken chain of comparisons. A documented system of } \\
\text { comparisons with each step having the essential elements of } \\
\text { metrological traceability going back to a standard acceptable to } \\
\text { the parties, usually a national or international standard; Are } \\
\text { suitable standards identified in the procedure? }\end{array}$ & \\
\hline
\end{tabular}




\begin{tabular}{|c|c|}
\hline $\begin{array}{l}\text { Method Evaluation } \\
\end{array}$ & Observations \\
\hline \multicolumn{2}{|l|}{$\begin{array}{l}\text { Standard Calibrations \& Intervals. Calibrations of standards } \\
\text { (and equipment where appropriate) must be repeated at } \\
\text { established (may be defined through measurement assurance) } \\
\text { and appropriate intervals to preserve metrological traceability of } \\
\text { the standard over time and use (see GLP 4, GMP 11); Are } \\
\text { suitable calibration intervals defined for the standards used in } \\
\text { this procedure? }\end{array}$} \\
\hline \multicolumn{2}{|l|}{$\begin{array}{l}\text { Documented Measurement Uncertainty. The measurement } \\
\text { uncertainty for each step in the traceability chain must be } \\
\text { calculated according to defined methods and must be stated so } \\
\text { that an overall uncertainty for the whole chain may be } \\
\text { calculated (see SOP 29); Is the uncertainty budget completely } \\
\text { defined based on a comparison of similar procedures or } \\
\text { technical reference documents (describe the procedures and/or } \\
\text { references) }\end{array}$} \\
\hline \multicolumn{2}{|l|}{$\begin{array}{l}\text { Documented Measurement Procedure. Each step in the chain } \\
\text { must be performed according to documented and generally } \\
\text { acknowledged procedures (see GMP 12) and the results must be } \\
\text { documented (i.e., in a calibration certificate, see SOP 1); Is the } \\
\text { procedure complete according to all required elements? } \\
\text { (4.d) }\end{array}$} \\
\hline \multicolumn{2}{|l|}{$\begin{array}{l}\text { Accredited Technical Competence. The laboratories or bodies } \\
\text { performing one or more steps in the chain must supply evidence } \\
\text { of technical competence (e.g., by maintaining appropriate } \\
\text { training records, participating in interlaboratory comparisons, } \\
\text { and by demonstrating that they are accredited by a recognized } \\
\text { accreditation body); Have all staff been trained and have they } \\
\text { demonstrated competency with the procedure? Have any other } \\
\text { laboratories provided input or tried to duplicate the procedure? } \\
\text { Was an interlaboratory comparison or proficiency test } \\
\text { conducted? Describe the results. }\end{array}$} \\
\hline \multicolumn{2}{|l|}{$\begin{array}{l}\text { Measurement assurance. A proper measurement assurance } \\
\text { program must be established to ensure the validity of the } \\
\text { measurement process and the accuracy of standard used at the } \\
\text { time of the measurement (see SOPs } 9,17,20,30 \text { ). What type of } \\
\text { measurement assurance is integrated into the procedure? } \\
\text { Describe what the measurement assurance monitors (standards, } \\
\text { process, both? How?) }\end{array}$} \\
\hline \multirow{2}{*}{\multicolumn{2}{|c|}{$\begin{array}{l}\text { Additional Assessments } \\
\text { Comparison of Results with Other Procedures. Describe what } \\
\text { other procedures or standards were considered and why/why } \\
\text { not chosen? Describe the results obtained and analysis } \\
\text { conducted with multiple procedures. }\end{array}$}} \\
\hline & \\
\hline $\begin{array}{l}\text { Evaluation of Accuracy and Bias. (5.f.ii) } \\
\text { What are the limits to bias or error? How do you know the } \\
\text { results are right? Describe the recently calibrated standard/set } \\
\text { of standards that were used. Describe any standard reference } \\
\text { materials that were used. How were the results assessed for } \\
\text { Accuracy? }\end{array}$ & \\
\hline
\end{tabular}




\begin{tabular}{|l|l||}
\hline \multicolumn{1}{|c||}{ Method Evaluation } & Observations \\
\hline \hline $\begin{array}{l}\text { Evaluation of Precision. How was data for repeatability } \\
\text { obtained? Describe whether the precision assessment is short- } \\
\text { term or long-term and if short-term, how do you know how the } \\
\text { procedure will repeat over time? How do you know whether the }\end{array}$ & \\
precision is sufficiently small when incorporated into & \\
uncertainties? Describe the statistical assessments that were & \\
completed and document the analysis results. & \\
\hline $\begin{array}{l}\text { Evaluation of Repeatability. E.g., two different units were } \\
\text { evaluated after a recent (enter dates) calibration by multiple }\end{array}$ & \\
metrologists; what kind of statistics were used and what were & \\
the results? (Consider repeatability with different staff, & \\
equipment, standards/nominal values, and not just short-term & \\
precision.) & \\
\hline Evaluation of Reproducibility. Have any other laboratories & \\
provided input or tried to duplicate the procedure? Was an & \\
interlaboratory comparison or proficiency test conducted? & \\
Describe the results. & \\
\hline $3^{\text {rd } \text { Party Assessment or Technical Reviews. Have any other }}$ & \\
technical experts reviewed the procedure and provided input? & \\
Describe their assessment and any recommended improvements & \\
or changes that were implemented because of the review. & \\
\hline
\end{tabular}

This procedure has found to be complete, fit for its intended use, technically validated, meets customer needs, and is approved for use.

Quality Manager Signature

Quality Manager Name (Printed)

Date
Technical Manager Signature

Technical Manager Name (Printed) 


\section{Appendix B}

\section{Example Outline for a Standard Operating Procedure}

\section{(Title)}

1 Scope and Measurand(s) of Calibrations

2 Description of the Item to be Calibrated

3 Measurement Parameters, Quantities, and Ranges to be Determined

4 Equipment, Including Technical Performance Requirements

5 Reference Standards and Reference Materials

6 Environmental Conditions and Stabilization Periods

$7 \quad$ Procedure Include any special items as noted in this list:

7.1 Affixing of identification marks, handling, transporting, storing and preparation of items;

7.2 Checks to be made before the work is started;

7.3 Checks that the equipment is working properly and, where required, calibration and adjustment of the equipment before each use;

7.4 Step by step process: the method of recording the observations, data to be recorded, data reduction, method of analysis, and presentation of results;

7.5 Any safety measures to be observed;

7.6 Criteria and/or requirements for approval/rejection where applicable;

7.7 Data to be recorded and method of analysis and presentation;

8 Calculations (See Possible Measurement Equations)

9 Measurement Assurance (possible Check Standards)

10 Uncertainties (include an Uncertainty Budget Table)

11 Calibration Certificate 
This page is intentionally blank. 


\section{GLP 15}

\section{Good Laboratory Practice}

for

\section{Software Quality Assurance}

\section{$1 \quad$ Introduction}

This is the metrology laboratory procedure for protecting, validating, and approving the accuracy of computer software and systems. All software and systems that affect reported measurement results, reported corrections, or uncertainties must be evaluated to comply with this document. All supporting software used in the laboratory to monitor the validity of measurement results must be validated as well.

The verification and validation process must occur at all phases of software life cycle (Figure 1). In addition to validating and verifying software, it is important to assess the knowledge, skills, and attitude of the metrologist and staff to ensure proper use and application of the software to ensure that no inadvertent measurement errors are introduced due to poor data entry, improperly validated software modifications, or general use in the laboratory.

The use/configuration of Commercial Off-The-Shelf (COTS) software in a laboratory is, by definition, considered software engineering, and must comply with good software engineering practices including these verification and validation methods. (Note: this includes but is not limited to spreadsheets like Excel $^{\mathrm{TM}}{ }^{1}$ and coding in programs like Visual Basic.)

2 Purpose

The purpose of this procedure is to ensure that software and systems do not contribute errors or additional uncertainty to any measurement process and to ensure that computer systems are adequately designed, developed, and secure; this is called Software Verification. Additionally, software is evaluated to make sure that the software is designed to comply with the requirements of the chosen Standard Operating Procedure (SOP) for calibration, uncertainty, and reporting; this is called Software Validation. Use of this procedure is designed to increase the usability and reliability of software used in the laboratory, increase the quality of work done, and reduce liability.

Responsibility and authority

3.1 For COTS software that does not have built in protections to prevent accidental changes during routine use, the Technical Manager implements a system of templates, cell protection, read only access, or other security measures to protect the local configuration.

\footnotetext{
${ }^{1}$ No approval or endorsement of any commercial product by the National Institute of Standards and Technology is intended or implied. Certain commercial equipment, instruments, or materials are identified in this paper to facilitate understanding. Such identification does not imply recommendation or endorsement by the National Institute of Standards and Technology, nor does it imply that the materials or equipment identified are necessarily the best available for the purpose.

GLP 15 - 2019

Page 1 of 11
} 
3.2 The Quality Manager/Laboratory Director is responsible for ensuring that this Standard Administrative Procedure (SAP) is followed and documented, and that all software associated with a measurement result has been validated. The Quality Manager/Laboratory Director is responsible to validate, or arrange to have another metrologist validate, all software. The Technical Manager ensures that numerical computations are correct, systems and software are adequately documented through instructions and/or manuals (at the level needed for accurate staff use), and presents evidence to the Laboratory Supervisor for approval using Form A (file associated with this procedure). It is important to note that self-validation is extremely difficult, thus in smaller laboratories, additional steps need to be taken to ensure good verification and validation of software. Additional steps may include interlaboratory evaluations of procedural files.

3.3 The Laboratory Director or Technical Manager coordinates with Information Technology staff (IT) regarding all laboratory software and computer requirements for the laboratory, including but not limited to updates to operating systems, operating software, network access, backup policies, file storage, file access, and retention.

3.4 The Technical Manager employs the following security measures to maintain the security of the disks where primary software resides to ensure that systems and software are protected from unauthorized access, safeguarded against tampering and loss; operated in an environment that complies with provider or laboratory specifications, maintained in such a manner as to ensure the integrity of data and information, and methods for ensuring data is not lost through system failures:

3.4.1 Metrology laboratory staff and Laboratory Director who have been trained in specific applications and procedures who should have access to the applicable disks/files are specified.

3.4.2 The IT staff will have access to files for emergency purposes, but are not authorized to perform software changes nor validate technical applications without suitable metrology training or technical knowledge of the procedure.

3.4.3 Regular backups are performed weekly (all files) and daily (modified files).

3.4.4 Restoration of software in the event of a disk failure.

3.5 Commercial Off-The-Shelf software packages are commonly used by laboratories and are sufficiently validated for all use; however, each laboratory must choose the software appropriately. Calculation results from commercial software must be evaluated during software testing and approval. Some spreadsheet functions, such as rounding or even simple calculations with large numbers and small differences, may not be adequate for the reporting of calibration results and must comply with the accuracy requirements of the procedure as well as other good laboratory 
practices. The modification and use of COTS spreadsheets in the laboratory are considered software engineering and must be validated.

3.6 A list of COTS software is maintained in the laboratory's Inventory and Assessment file (see Form B a file associated with this procedure).

$4 \quad$ Software Engineering

Good software engineering includes phases for setting requirements, designing, constructing, testing, installing, validating, documenting, performing operations and maintenance, and retiring the software when appropriate. All phases are important aspects to consider when validating software. See the software life cycle (Figure 1 ) for the workflow. ${ }^{2}$ Form A methods and questions should be considered during all phases of the software life cycle.

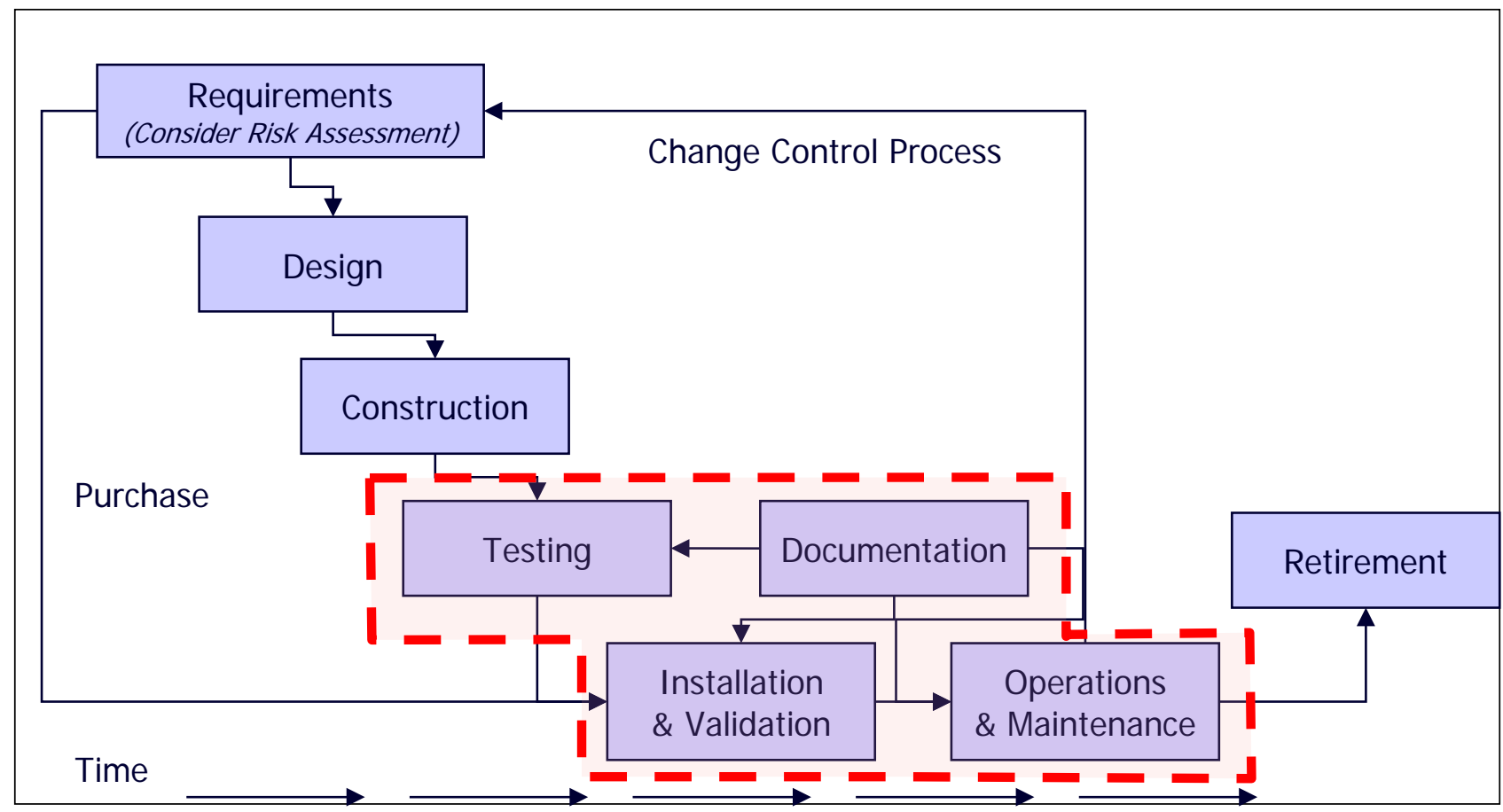

Figure 1. Software Life Cycle

\subsection{Software Life Cycle}

\subsubsection{Requirements Phase}

This phase identifies, specifies, analyzes, and documents all the requirements that the software must satisfy regarding functionality, performance, design constraints, attributes, and external interfaces. It is important to perform a risk assessment during this phase.

\subsubsection{Design Phase}

${ }^{2}$ NCSLI Recommended Practice (RP) 13, 1996. Figure 1 as modified.

GLP 15 - 2019

Page 3 of 11 
4.1.3 This phase develops, documents, and reviews a design that satisfies the requirements previously documented.

\subsubsection{Construction Phase}

4.1.5 This phase takes each element documented in the design phase and translates it into a programming language, and may incorporate COTS software or rely on it solely. This phase is often known as a "coding” or "build” phase.

\subsubsection{Testing Phase}

4.1.7 This phase runs the software through test cases and analyzes any failure to determine which phase contributed to such error.

\subsubsection{Installation and Validation Phase}

4.1.9 This phase executes tests for the installation and integration of the software into the equipment (i.e., other software, data, hardware), and the documentation of the approval of the software for operational use. User site testing is a very important practice to consider because it helps eliminate errors (i.e., bugs) that may arise after the software is installed on different equipment. Form A (file associated with this procedure) must be used to ensure complete assessment of all aspects of the software (especially ensuring that calculation functions are not the only item assessed) and to begin the documentation.

\subsubsection{Documentation Phase}

4.1.11 This phase handles the technical documentation of all the phases described above. Evidence must be retained in association with the methods used in Form A (file associated with this procedure).

\subsubsection{Operations and Maintenance}

4.1.13 Once the software has been approved for operational use, routine maintenance may be performed to remove errors, to respond to new or modified equipment, or to adapt the software to changes in the operating environment. All planned changes must be approved by the Laboratory Director or Technical Manager before work is started. After any modifications, software must be verified and validated again.

\section{$5 \quad$ Risk Analysis}

Software is considered of higher risk when calibration measurement results and uncertainty values are used on calibration certificates and provided to the customer. 
Where the software is developed by someone else, for example, configuration of COTS software, the final user (laboratory) must study the information provided by the supplier to properly assess the risk of usage, as the supplier may have a different application in mind, errors may not have been discovered, or software may not be completely validated. ${ }^{3}$

$6 \quad$ Methods and Practices for Evaluation

\subsection{Documentation}

Documentation of the verification and validation of all computer systems and software is maintained in the laboratory. These files include an inventory of laboratory computers, COTS software, laboratory-developed software, and a copy of the "Inventory and Assessment" Excel file.

Each laboratory spreadsheet has a worksheet/tab for document control/revisions, a worksheet/tab for instructions, and verification/validation worksheet/tab (or the verification/validation is maintained in other appropriate files). Revisions are documented in each file and include: version control, details of changes that have been made and indications of staff approvals. Instructions include how to use the software and reference any prerequisite training or knowledge staff must have to use the software. The verification/validation tab may include the Technical Assessment of Software (Form A) or separate documentation may be retained in the laboratory.

\subsection{Assessment}

Technical assessment of software includes, but may not be limited to, completion of Form A (file associated with this procedure), with all associated objective evidence retained with the summary evaluations.

This assessment is to be performed during the design and development phase, upon installation, whenever operating systems change, when software is moved, and when software is updated and must be verified at all work stations.

\subsection{Assessment Methods and Examples of Evidence}

The following table provides a brief overview of the assessment methods used to evaluate software and complete Form A.

\footnotetext{
${ }^{3}$ For additional information on Risk Analysis practices and procedures, see Validation of software in measurement systems (Software for Metrology Best Practice Guide No. 1), National Physical Laboratory (NPL), http://www.npl.co.uk/. 
Table 1. Validation Methods and Example Assessments.

\begin{tabular}{|c|c|c|c|}
\hline \multicolumn{2}{|c|}{ Validation Method } & \multirow[b]{2}{*}{$\begin{array}{l}\text { Descriptions } \\
\text { Review the software. Is it clear and does it make } \\
\text { sense? Are there instructions for use? Are data } \\
\text { entry fields labeled and color coded? Is it } \\
\text { obvious what procedure is being used? Is there } \\
\text { adequate documentation for a metrologist who is } \\
\text { trained in this procedure to know what and } \\
\text { where data is entered? Are they able to ensure } \\
\text { that no data entry is inadvertently left out? Is the } \\
\text { spreadsheet "blank" when opened to make sure } \\
\text { old data is not accidentally used? Is there } \\
\text { traceability to the specifications document (often } \\
\text { an SOP)? Are cells formatted appropriately? Are } \\
\text { unused cells locked? Are unused sheets } \\
\text { removed? Are worksheets named appropriately? } \\
\text { (Basically, were good spreadsheet design } \\
\text { concepts followed?) }\end{array}$} & \multirow[b]{2}{*}{$\begin{array}{l}\text { Evidence } \\
\\
\text { Evidence: describe the review that } \\
\text { was conducted in a few sentences. }\end{array}$} \\
\hline A & $\begin{array}{l}\text { Software } \\
\text { inspection }\end{array}$ & & \\
\hline B & $\begin{array}{l}\text { Mathematical } \\
\text { specification }\end{array}$ & $\begin{array}{l}\text { Is the correct SOP used? Are the correct } \\
\text { formulae selected? E.g., SOP } 2 \text { for air density } \\
\text { has } 2 \text { formulas and one is recommended - which } \\
\text { one was used? Is it the one you want used at the } \\
\text { reported level of precision/uncertainty? Is there } \\
\text { direct traceability of the equations? }\end{array}$ & $\begin{array}{l}\text { Evidence: } \\
\text { Include a "documentation" } \\
\text { worksheet in your workbooks that } \\
\text { identify which SOP and equations } \\
\text { are used. }\end{array}$ \\
\hline C & Code review & $\begin{array}{l}\text { Compare the cells with the formulae line by line } \\
\text { in the spreadsheet versus the SOP. Do they } \\
\text { match exactly? Are repeated calculations copied } \\
\text { exactly or appropriately referencing the correct } \\
\text { cells? Is rounding done at the appropriate } \\
\text { locations in the file? }\end{array}$ & $\begin{array}{l}\text { Evidence: } \\
\text { Save one of the worksheets in your } \\
\text { workbook with the equations } \\
\text { showing and notes included to show } \\
\text { that they were evaluated - include a } \\
\text { "reference" column to show which } \\
\text { section of the SOP was compared. } \\
\text { E.g., "compared to equation 3.2.2. } \\
\text { in SOP 4." Include a graphic } \\
\text { capture of the equation to support } \\
\text { the comparison further. }\end{array}$ \\
\hline $\mathrm{D}$ & $\begin{array}{l}\text { Numerical } \\
\text { stability }\end{array}$ & $\begin{array}{l}\text { This component of Excel needs to be evaluated } \\
\text { for rounding practices and the stability of } \\
\text { precision calculations. } \\
\text { See the NPL example in Best Practice Guide } \\
\text { Number } 1 \text {. }\end{array}$ & \\
\hline
\end{tabular}




\begin{tabular}{|c|c|c|c|}
\hline \multicolumn{2}{|c|}{ Validation Method } & Descriptions & Evidence \\
\hline $\mathrm{E}$ & $\begin{array}{l}\text { Component } \\
\text { testing }\end{array}$ & $\begin{array}{l}\text { Components include things like Pass/Fail tests, } \\
\text { color coding, automatic look-ups for standards } \\
\text { or uncertainties from a master list/table or } \\
\text { master file. They might include automatic report } \\
\text { generation macros. Depending on the } \\
\text { component, you will need to create different } \\
\text { kinds of approaches for the components and the } \\
\text { evidence may include a description or saved } \\
\text { examples. } \\
\text { Have you tested the functionality of each } \\
\text { functional macro? Each command/button? } \\
\text { Combinations of interdependent macros? } \\
\text { Accuracy of plotted graphs? } \\
\text { Printing of each printable worksheet/report? }\end{array}$ & $\begin{array}{l}\text { Evidence: } \\
\text { Pass/Fail: intentionally enter good } \\
\text { or bad data to see if the criteria } \\
\text { changes. } \\
\text { Conditional color formatting: most } \\
\text { often used as a pass/fail or marginal } \\
\text { flag - enter good, bad, and marginal } \\
\text { data to determine the response. } \\
\text { Look up tables: sample (or do } 100 \% \\
\text { evaluations) the look up tables to } \\
\text { make sure items are selected from } \\
\text { the right row, column, cell, and } \\
\text { workbook. } \\
\text { Make sure data is transferred } \\
\text { accurately for automation from } \\
\text { laboratory instruments and } \\
\text { transferred accurately to the final } \\
\text { calibration report. }\end{array}$ \\
\hline $\mathrm{F}$ & $\begin{array}{l}\text { Numerical } \\
\text { reference results }\end{array}$ & $\begin{array}{l}\text { Two aspects need to be considered here: } \\
\text { 1. All data in tables and lists match their } \\
\text { reference sources exactly; and } \\
\text { 2. All values with automatic look up } \\
\text { features need to select the correct row, } \\
\text { column, cell, and workbook. } \\
\text { Do look up tables and lists match the latest } \\
\text { calibration report? Do uncertainties match the } \\
\text { latest Scope? If values reference another } \\
\text { workbook or spreadsheet, is it dated - and if you } \\
\text { update the date on a master list of standards, } \\
\text { does the file reference a default value, old value, } \\
\text { or zero instead of an error message? }\end{array}$ & $\begin{array}{l}\text { Evidence: } \\
\text { Print reference values and do line by } \\
\text { line comparisons to ensure they } \\
\text { match. Alternatively, scan a graphic } \\
\text { and do the line by line comparison } \\
\text { in the workbook. }\end{array}$ \\
\hline G & $\begin{array}{l}\text { Embedded data } \\
\text { evaluation }\end{array}$ & $\begin{array}{l}\text { Sometimes conversion factors, reference values, } \\
\text { or other mathematical factors are included in a } \\
\text { calculation. E.g., air density and water density } \\
\text { equations have many standard multipliers with } \\
\text { many decimal places. } \\
\text { Conversion factors need to be the most accurate } \\
\text { ones available and need to be rounded, when } \\
\text { appropriate, to the right number of digits to } \\
\text { avoid impacting the final results. Even without } \\
\text { look-up values, some values for standards or } \\
\text { uncertainties may be embedded in a working file } \\
\text { and the accuracy of those values must be } \\
\text { ensured. }\end{array}$ & $\begin{array}{l}\text { Evidence: } \\
\text { Identify all embedded values in a } \\
\text { list (ideally within the spreadsheet) } \\
\text { and compare them to the correct } \\
\text { reference values and note the date of } \\
\text { the comparison. The dates will help } \\
\text { ensure that if subsequent conversion } \\
\text { factors are used or standards are } \\
\text { calibration the right values are } \\
\text { entered. }\end{array}$ \\
\hline
\end{tabular}

GLP 15 - 2019

Page 7 of 11 


\begin{tabular}{|c|c|c|c|}
\hline \multicolumn{2}{|c|}{ Validation Method } & \multirow[b]{2}{*}{$\begin{array}{l}\text { Descriptions } \\
\text { Data that is published in an SOP, generated by } \\
\text { the laboratory, used for a proficiency test, or } \\
\text { even simply created for testing purposes may be } \\
\text { used. } \\
\text { Do two spreadsheets - created by different } \\
\text { people - perhaps in different software - agree? } \\
\text { Does a newer spreadsheet agree with an older } \\
\text { spreadsheet down to the level of intermediate } \\
\text { calculations? If there are differences, do they } \\
\text { agree well beyond the level where they could } \\
\text { impact the uncertainty of the calibration? }\end{array}$} & \multirow[b]{2}{*}{\begin{tabular}{l}
\multicolumn{1}{c}{ Evidence } \\
\\
Evidence: \\
Be sure to save both spreadsheet \\
files and note file names and dates \\
of evaluation.
\end{tabular}} \\
\hline $\mathrm{H}$ & $\begin{array}{l}\text { Back-to-back } \\
\text { testing }\end{array}$ & & \\
\hline I & $\begin{array}{l}\text { Analysis without } \\
\text { computer } \\
\text { assistance (data } \\
\text { sets) }\end{array}$ & $\begin{array}{l}\text { Data that is published in an SOP, generated by } \\
\text { the laboratory, used for a proficiency test, or } \\
\text { even simply created for testing purposes may be } \\
\text { used. } \\
\text { Do hand calculations with a scientific calculator } \\
\text { (hand or "computer calculator") agree with those } \\
\text { generated by the spreadsheet? }\end{array}$ & $\begin{array}{l}\text { Evidence: } \\
\text { Be sure to save the spreadsheet file } \\
\text { and a copy of the hand-written } \\
\text { notes; record the dates of } \\
\text { evaluation. }\end{array}$ \\
\hline $\mathrm{J}$ & Security & $\begin{array}{l}\text { Can a metrologist accidentally delete equations } \\
\text { and calculation cells that should be protected? } \\
\text { Can cells be accidentally moved around? Is it } \\
\text { possible for an untrained metrologist to } \\
\text { "correct" something by mistake because } \\
\text { passwords are readily available? } \\
\text { How are all files backed up? Is there a source of } \\
\text { the back-up files maintained in an alternate } \\
\text { facility/location? Can the files on network drives } \\
\text { accidentally be deleted? If a computer fails (or } \\
\text { facility damaged where the computer can no } \\
\text { longer be used, is there a back-up somewhere? }\end{array}$ & $\begin{array}{l}\text { Evidence: } \\
\text { Describe the review that was } \\
\text { conducted in a few sentences. }\end{array}$ \\
\hline
\end{tabular}

In addition to following this procedure in the laboratory, the software development process assumes the knowledge and familiarity of the operator with this procedure and with the applicable procedure being evaluated. It is critical for the operator to pay attention while using any software to find potential data-entry errors as they occur. One might call this real-time validation based on the operator's experience, knowledge, and judgment.

The level of confidence, therefore the level of software validation, verification, and testing effort needed, varies depending upon the risk posed by the software.

\section{$7 \quad$ Acknowledgement and Validation}

This publication was presented as part of a collection of draft Standard Administrative Procedures in 1996 and has been adopted by many weights and measures laboratories in some form since that time. The procedure has also been used in NIST seminars covering software verification and validation as a part of compliance with ISO/IEC 17025. 


\section{Appendix A}

\section{Software Verification and Validation Form}

\begin{tabular}{|l|l|}
\hline Laboratory: & Date: \\
\hline Software Description: & Version: \\
\hline
\end{tabular}

\begin{tabular}{|c|c|c|c|}
\hline Codes & Assessment & Pass/Fail & $\begin{array}{c}\text { Result/Observations (Attach Evidence or } \\
\text { Describe) }\end{array}$ \\
\hline \multirow{17}{*}{ 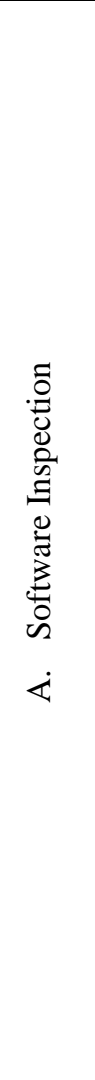 } & Spreadsheet is clear and makes sense & & \\
\hline & There are instructions for use & & \\
\hline & $\begin{array}{l}\text { Instructions and data input appear on the visible } \\
\text { portion of the first worksheet }\end{array}$ & & \\
\hline & $\begin{array}{l}\text { Data-entry fields are labeled and color coded (it } \\
\text { is recommended to avoid red and green) }\end{array}$ & & \\
\hline & $\begin{array}{l}\text { The type/name of procedure used is clearly } \\
\text { specified }\end{array}$ & & \\
\hline & $\begin{array}{l}\text { The number of digits to be rounded to is } \\
\text { specified }\end{array}$ & & \\
\hline & $\begin{array}{l}\text { The user is warned/notified whenever data-entry } \\
\text { fields are left blank }\end{array}$ & & \\
\hline & $\begin{array}{l}\text { Data-entry fields are "blank" when opened, } \\
\text { preventing loss of old data and ensuring that old } \\
\text { data is not used with the current calculations }\end{array}$ & & \\
\hline & $\begin{array}{l}\text { The software opens at the right location within } \\
\text { the file }\end{array}$ & & \\
\hline & Unused fields/cells are locked & & \\
\hline & $\begin{array}{l}\text { Rows/columns that the operator need not see are } \\
\text { hidden }\end{array}$ & & \\
\hline & Unused worksheets are removed & & \\
\hline & Worksheets are named appropriately & & \\
\hline & Pass/Fail criteria are specified in instructions & & \\
\hline & Pass/Fail cells are automated (Not data-entry) & & \\
\hline & Calculation fields are properly labeled & & \\
\hline & Units are expressed properly and correctly & & \\
\hline \multirow{4}{*}{ 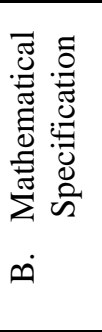 } & The appropriate procedure is used & & \\
\hline & $\begin{array}{l}\text { The formulae and methods chosen from that } \\
\text { procedure are specified }\end{array}$ & & \\
\hline & \begin{tabular}{|l|}
$\begin{array}{l}\text { Sources and references for formulae are } \\
\text { specified }\end{array}$ \\
\end{tabular} & & \\
\hline & $\begin{array}{l}\text { The chosen procedure, its methods, and its } \\
\text { formulae, are appropriate to the level of } \\
\text { precision/uncertainty }\end{array}$ & & \\
\hline
\end{tabular}




\begin{tabular}{|c|c|c|c|}
\hline Codes & Assessment & Pass/Fail & $\begin{array}{c}\text { Result/Observations (Attach Evidence or } \\
\text { Describe) }\end{array}$ \\
\hline \multirow{3}{*}{ 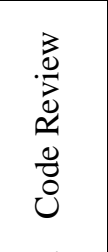 } & $\begin{array}{l}\text { The formulae in the fields exactly match the } \\
\text { procedure }\end{array}$ & & \\
\hline & $\begin{array}{l}\text { Repeated calculations appropriately reference the } \\
\text { correct cells }\end{array}$ & & \\
\hline & $\begin{array}{l}\text { Calculations, when tested using standard data or } \\
\text { reference test data, show appropriate accuracy }\end{array}$ & & \\
\hline ن & $\begin{array}{l}\text { Rounding is done at the appropriate locations in } \\
\text { the file }\end{array}$ & & \\
\hline \multirow{3}{*}{ 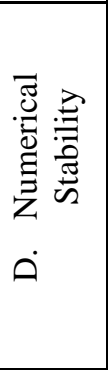 } & $\begin{array}{l}\text { Calculations are stable as determined by an } \\
\text { evaluation that uses large numbers and small } \\
\text { differences. }\end{array}$ & & \\
\hline & $\begin{array}{l}\text { Fields, therefore their content, are categorized as } \\
\text { "Number" and not "General" when appropriate, } \\
\text { and vice versa }\end{array}$ & & \\
\hline & $\begin{array}{l}\text { "Number" cells are locked to a limited number } \\
\text { of decimal places; this limit is appropriate to the } \\
\text { values being used }\end{array}$ & & \\
\hline \multirow{9}{*}{ 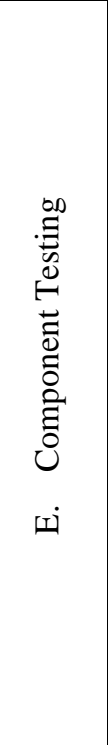 } & $\begin{array}{l}\text { Conditional logic cells handle negative values } \\
\text { properly }\end{array}$ & & \\
\hline & $\begin{array}{l}\text { Conditional logic cells withstand a Boundary } \\
\text { Value test }\end{array}$ & & \\
\hline & Each macro used is functional & & \\
\hline & Each command/button is functional & & \\
\hline & $\begin{array}{l}\text { Combinations of interdependent macros are } \\
\text { functional }\end{array}$ & & \\
\hline & Plotted graphs are accurate & & \\
\hline & Plotted graphs and its axes are properly labeled & & \\
\hline & Worksheets/reports print properly, if needed to & & \\
\hline & $\begin{array}{l}\text { Conditional (color and non-color) formatting is } \\
\text { functional }\end{array}$ & & \\
\hline \multirow{4}{*}{ 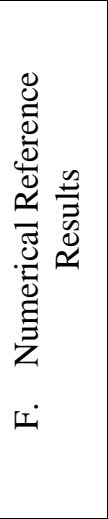 } & $\begin{array}{l}\text { Look-up tables and lists match the latest } \\
\text { calibration report. }\end{array}$ & & \\
\hline & Uncertainties match the latest Scope & & \\
\hline & $\begin{array}{l}\text { Values that reference another workbook or } \\
\text { spreadsheet are dated }\end{array}$ & & \\
\hline & $\begin{array}{l}\text { When a master list's date is updated, the file } \\
\text { references (A) an old value, (B) a default value, } \\
\text { (C) displays zero or (D) an error message, as } \\
\text { desired by the user }\end{array}$ & & \\
\hline
\end{tabular}

GLP 15 - 2019 


\begin{tabular}{|c|c|c|c|}
\hline Codes & Assessment & Pass/Fail & $\begin{array}{c}\text { Result/Observations (Attach Evidence or } \\
\text { Describe) }\end{array}$ \\
\hline \multirow{3}{*}{ 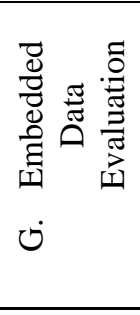 } & $\begin{array}{l}\text { Embedded data (conversion factors, reference } \\
\text { values, etc) is correct }\end{array}$ & & \\
\hline & $\begin{array}{l}\text { The evaluation of the embedded data is dated } \\
\text { and documented }\end{array}$ & & \\
\hline & $\begin{array}{l}\text { The instructions worksheet includes a list of all } \\
\text { additional files and plug-ins needed for it to run } \\
\text { properly }\end{array}$ & & \\
\hline 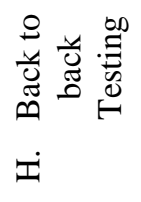 & $\begin{array}{l}\text { Newer spreadsheets and older spreadsheets } \\
\text { agree down to the level of intermediate } \\
\text { calculations; this evaluation is dated and } \\
\text { documented }\end{array}$ & & \\
\hline \multirow{2}{*}{ 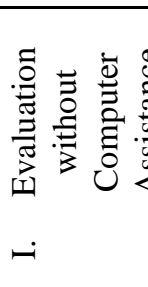 } & $\begin{array}{l}\text { Hand calculations agree with those generated by } \\
\text { the spreadsheet, or if they disagree, the } \\
\text { differences are significantly smaller than the } \\
\text { reported uncertainty }\end{array}$ & & \\
\hline & $\begin{array}{l}\text { Conclusions and results are apparent (if } \\
\text { appropriate) }\end{array}$ & & \\
\hline \multirow{6}{*}{ 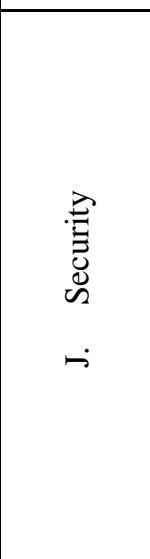 } & $\begin{array}{l}\text { Equation and calculation cells are protected } \\
\text { against inadvertent editing }\end{array}$ & & \\
\hline & $\begin{array}{l}\text { Cells are locked in place; they cannot be } \\
\text { moved/dragged }\end{array}$ & & \\
\hline & Confidentiality of passwords is appropriate & & \\
\hline & Files are backed up automatically & & \\
\hline & $\begin{array}{l}\text { Additional back-up is available at alternate } \\
\text { facilities }\end{array}$ & & \\
\hline & $\begin{array}{l}\text { Files on network drives cannot be accidentally } \\
\text { deleted }\end{array}$ & & \\
\hline
\end{tabular}


This page is intentionally blank. 


\section{Standard Operating Procedures}


This page is intentionally blank. 
SOP 22

Standard Operating Procedure

for

\section{Calibration of Traffic Speed Gun Tuning Forks and}

other Acoustic Frequency Emitting Devices

1 Introduction

\section{$1.1 \quad$ Purpose}

This Standard Operating Procedure (SOP) describes the procedure to be followed for the calibration of tuning forks which are used to certify traffic control speed guns, and for calibration of other acoustic frequency emitting devices. The procedure may also be used to calibrate tuning forks for applications such as musical tuning. This procedure utilizes either 1) a Global Positioning System Disciplined Oscillator (GPSDO) or 2) an electronic frequency counter that is directly compared to the NIST transmitted frequency standards to reference the Coordinated Universal Time (UTC) standard maintained by the NIST and the United States Naval Observatory (USNO). The accuracy of the calibration is limited by the mechanical instability of the device being tested. Detailed measurement ranges, standards, equipment, and uncertainties for this SOP are generally compiled in a separate document in the laboratory.

\subsection{Applicable References}

1.2.1 Speed-Measuring Device Performance Specifications: Across-the-Road Radar Module, DOT HS 812 266, Department of Transportation, National Highway Traffic Safety Administration (NHTSA).

1.2.2 NIST SP 432: NIST Time and Frequency Services.

1.2.3 The Use of GPS Disciplined Oscillators as Primary Frequency Standards for Calibration and Metrology Laboratories, M. Lombardi, NCSLI Measure J. Meas. Sci., vol. 3, no. 3, pp. 56-65, September 2008.

1.2.4 Evaluating the Frequency and Time Uncertainty of GPS Disciplined Oscillators and Clocks, M. Lombardi, NCSLI Measure J. Meas. Sci., vol. 11, no. 3-4, pp. 30-44, December 2016.

1.2.5 Time and Frequency Measurements Using the Global Positioning System, Michael A. Lombardi, Lisa M. Nelson, Andrew N. Novick, Victor S. Zhang, Cal Lab Magazine, July, August, September 2001.

1.2.6 NIST Time and Frequency Broadcasts from Radio Stations WWVB, WWV, and WWVH, Matthew Deutch, Ernie Farrow, John Lowe, Glenn Nelson, Dean Okayama, Don Patterson, Douglas Sutton, and William Yates, 2001 NCSLI Workshop and Symposium. 
1.2.7 Calibration of Police Radar Instruments, D. W. Allan (NBS), F. H. Brzoticky (CO Dept. of Agriculture), NBS Special Publication 442, Report of the National Conference on Weights and Measures, 1976.

\subsection{Prerequisites}

1.3.1 Verify that the metrologist is experienced in making frequency measurements.

1.3.2 Verify that suitable check standards are present and used in an active measurement assurance program.

1.3.3 Verify the laboratory environment is within an acceptable temperature and humidity range.

Table 1. Environmental limits for calibrations.

\begin{tabular}{|c|c|}
\hline \hline Temperature & Relative Humidity \\
\hline $18{ }^{\circ} \mathrm{C}$ to $25^{\circ} \mathrm{C}$ & $40 \%$ to $60 \%$ \\
\hline
\end{tabular}

2 Methodology

\subsection{Summary}

A tuning fork, or other acoustic frequency emitting device, is calibrated by measuring its acoustic frequency with an electronic frequency counter that is calibrated, and has metrological traceability through the L1 1 575.42 MHz GPS signal broadcast by the United States Air Force from Colorado Springs, Colorado, referencing the U.S. Naval Observatory (USNO) Coordinated Universal Time (UTC) standard or through comparison with the NIST transmitted radio frequency signal (WWV, WWVH), or telephone frequency signal. No adjustments are made to tuning forks; they are either approved or rejected. Because U.S. law enforcement personnel traditionally use U.S. Customary units, units of miles per hour (mph) are referenced throughout this SOP.

\subsection{Equipment / Apparatus}

2.2.1 An electronic frequency counter capable of 0.1 hertz $(\mathrm{Hz})$ resolution throughout the range from direct current (DC) to $10000 \mathrm{~Hz}$.

2.2.2 A transducer to convert sound energy to electrical (DC) energy. The output must be strong enough for counter input sensitivity requirements.

2.2.2.1 A clamping type contact microphone, e.g., Signal Flex SF-30 Universal Tuner Pickup, or similar, is preferable for tuning forks. 
2.2.2.2 A microphone, e.g., Shure SM57, Cardioid, Dynamic, or similar, is preferred for other acoustic frequency emitting devices.

2.2.3 A GPS time and frequency reference receiver with antenna.

2.2.4 A short-wave receiver and antenna.

2.2.5 A calculator if converting frequency $(\mathrm{Hz})$ to miles per hour (mph).

2.2.6 A thermometer to measure ambient temperature.

2.3 Reference, Option A, Use of GPSDO

2.3.1 The tuning fork, or other acoustic frequency emitting device, must be in temperature equilibrium with the laboratory environment, typical equilibration time is not less than 2 hours. Read and record the ambient temperature.

2.3.2 Verify that the GPS frequency counter displays "ExtRef" on the display prior to use. This indicates the unit is utilizing the GPS reference receiver output as its reference.

2.3.3 Confirm that the GPS reference receiver signal light is illuminated indicating a locked signal.

2.3.4 Adjust the frequency counter to a gate setting interval of $0.2 \mathrm{~s}$ to $0.5 \mathrm{~s}$.

2.4 Reference, Option B, Use of Short-wave Receiver and NIST-transmitted Radio Signal.

2.4.1 The tuning fork, or other acoustic frequency emitting device, must be in temperature equilibrium with the laboratory environment, typical equilibration time is not less than 2 hours. Read and record the ambient temperature. 


\subsubsection{Assemble the system as shown in Figure 1.}

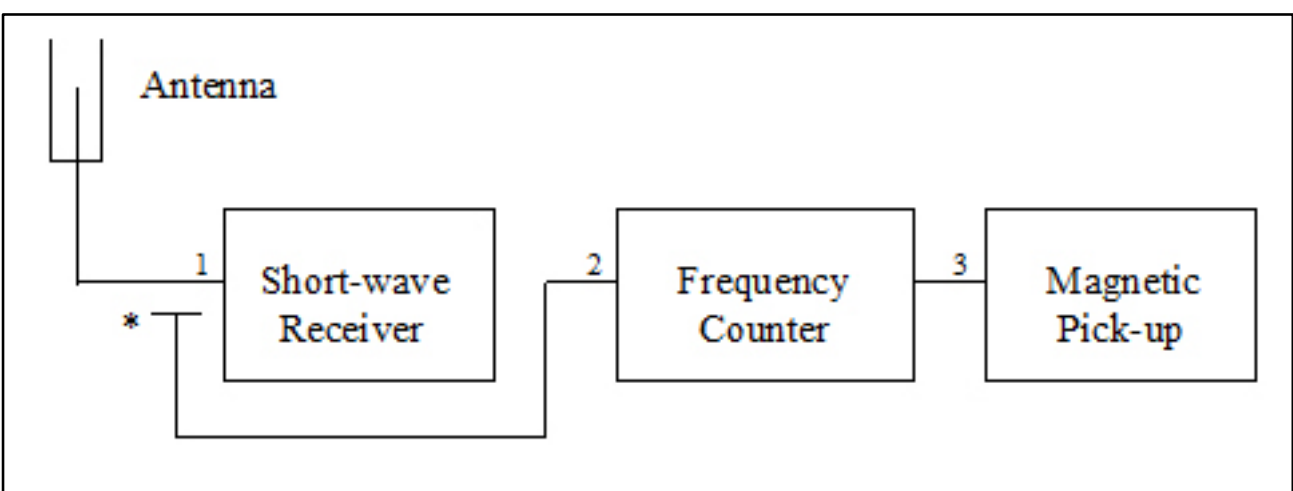

Figure 1. System Configuration.

2.4.3 Tune the short-wave receiver to the best usable standard frequency of $2.5 \mathrm{MHz}, 5 \mathrm{MHz}, 10 \mathrm{MHz}, 15 \mathrm{MHz}$, or $20 \mathrm{MHz}$.

2.4.3.1 If the $10 \mathrm{MHz}$ signal is not usable, a frequency divider / multiplier must be inserted at the frequency counter standard frequency output. Set the divider / multiplier to convert the 10 $\mathrm{MHz}$ standard frequency output to the best usable WWV(H) frequency.

2.4.3.2 Because of heterodyning, the received WWV signal and the counter standard frequency output will cause the short-wave receiver field strength meter to oscillate. The oscillation rate is directly proportional to the frequency difference between the two signals.

If the meter oscillates three complete cycles or less in 1 second, the frequency counter is accurate enough for tuning fork certification.

If the meter oscillates more than three cycles in 1 second or does not oscillate at all, consult the maintenance manual for "time base oscillator adjustment procedures" or refer the counter to a manufacturer's authorized repair facility. 
2.5 Reference, Option C, Use of Tuning Fork Gauge and NIST-transmitted Radio Signal.

2.5.1 The tuning fork, or other acoustic frequency emitting device, must be in temperature equilibrium with the laboratory environment, typical equilibration time is not less than 2 hours. Read and record the ambient temperature.

2.5.2 Verify accuracy of the Tuning Fork Gauge via the NIST telephone signal broadcast via a telephone connection pick-up coil.

Table 2. Reference calibration sources.

\begin{tabular}{|c|c|c|c|c|}
\hline Service & Location & $\begin{array}{l}\text { Telephone } \\
\text { Number }\end{array}$ & $\begin{array}{c}\text { Radio Call } \\
\text { Letters }\end{array}$ & $\begin{array}{c}\text { Broadcast } \\
\text { Frequencies }\end{array}$ \\
\hline NIST & Ft. Collins, CO & (303) 499-7111 & WWV & $\begin{array}{l}2.5 \mathrm{MHz} \\
5 \mathrm{MHz} \\
10 \mathrm{MHz} \\
15 \mathrm{MHz} \\
20 \mathrm{MHz}\end{array}$ \\
\hline $\begin{array}{l}\text { NIST } \\
\end{array}$ & Kauai, HI & (808) 335-4363 & $\begin{array}{l}\text { WWVH } \\
\end{array}$ & $\begin{array}{l}2.5 \mathrm{MHz} \\
5 \mathrm{MHz} \\
10 \mathrm{MHz} \\
15 \mathrm{MHz} \\
\end{array}$ \\
\hline $\begin{array}{l}\begin{array}{l}\text { U.S. Naval } \\
\text { Observatory } \\
\text { (USNO) }\end{array} \\
\end{array}$ & District of Columbia & $\begin{array}{l}\text { (202) 662-1401 } \\
\text { (202) } 762-1069\end{array}$ & ----- & ----- \\
\hline USNO & Colorado Springs, CO & $\begin{array}{l}\text { (719) 567-6742 } \\
\end{array}$ & ----- & ----- \\
\hline $\begin{array}{l}\text { National } \\
\text { Research Council } \\
\text { (NRC) }\end{array}$ & Ottawa, Ontario, Canada & $\begin{array}{l}\text { (613) 745-1576 } \\
\text { (English) } \\
\text { (613) 745-9426 } \\
\text { (French) }\end{array}$ & CHU & $\begin{array}{l}3.33 \mathrm{MHz} \\
7.850 \mathrm{MHz} \\
14.67 \mathrm{MHz}\end{array}$ \\
\hline
\end{tabular}

2.5.3 If the gauge meets accuracy requirements, continue with measurements of the tuning forks. If the gauge does not meet accuracy requirements, it is removed from service and submitted for calibration and adjustment to the manufacturer.

2.6 Procedure, Measure the Tuning Fork Frequency.

2.6.1 Grasp the tuning fork with the clamping type contact microphone near the serial numbered end of the fork. Avoid touching the tuning fork as much as possible to minimize warming the tuning fork thus changing its frequency. Strike the tuning fork with a semi-hard object, e.g., a wood block or a plastic mallet, etc. and immediately place the tuning fork $2.5 \mathrm{~cm}$ to $10 \mathrm{~cm}$ away from the receiver (alternatively, strike the tuning fork with the material while it is placed near the receiver). Never use a metallic or stone object to strike the tuning fork. Observe the frequency 
immediately and record the frequency and temperature at the time of the measurement.

2.6.2 Repeat previous step with the tuning fork grasped 180 degrees from the first reading (flip the tuning fork over) and striking the alternate tine.

2.6.3 Repeat previous step again with the tuning fork grasped 180 degrees from the second reading (flip the tuning fork over again) and strike the original tine.

2.6.4 Record the average of the three recorded readings as the oscillation frequency of the tuning fork.

2.7 Take readings of an acoustic frequency emitting device.

2.7.1 Utilize a microphone for this process.

2.7.2 Strike the acoustic frequency emitting device with a semi-hard instrument, e.g., a wood block or a plastic mallet, etc. while the system is placed $2.5 \mathrm{~cm}$ to $10 \mathrm{~cm}$ away from the receiver. Never use a metallic or stone object. Observe the frequency immediately and record the frequency and temperature.

2.7.3 Repeat the process until a minimum of three stable observations are achieved. This may involve adjusting the proximity of the microphone to the device being tested.

2.7.4 Average the stable frequency observations and record this as the frequency for the item being calibrated.

3 Calculations for Tuning Forks.

3.1 Multiply the average recorded measurement result (tuning fork oscillation frequency) by the appropriate conversion factor shown in Table 4 or use Equation 2 as shown in section 3.2. The calculation of the tuning fork speed, in miles per hour, is determined from Eqn. 1. The speed of light is slower in air than the defined vacuum speed.

$$
v=f_{d} \frac{c}{2 f_{0}}
$$




\subsubsection{Symbols Used in this Procedure}

Table 3. Symbols used in the procedure.

\begin{tabular}{|c|l|}
\hline Symbol & \multicolumn{1}{|c|}{ Description } \\
\hline$v$ & $\begin{array}{l}\text { calculated speed for the tuning fork in miles per } \\
\text { hour (mph) }\end{array}$ \\
\hline$f_{d}$ & measured tuning fork frequency \\
\hline$c$ & $\begin{array}{l}\text { speed of light in miles per hour; The speed of light } \\
\text { is an internationally accepted constant defined to be } \\
\text { exactly } 299792458 \mathrm{~m} / \mathrm{s} \text { (approximately } \\
670616629.3843951 \mathrm{mph}) \text {. The offset amount, } \\
\text { considered insignificant here, is determined by air } \\
\text { pressure, humidity, temperature, pollution amount } \\
\text { and type, etc. }\end{array}$ \\
\hline$f_{0}$ & designated radar band frequency \\
\hline
\end{tabular}

3.2 Table 4 has calculated values for conversion factors from $\mathrm{Hz}$ to $\mathrm{mph}$ for simplicity and is determined by the band and frequency but may be calculated using Eqn. 2. Unique factors for Kustom Signals, Inc. forks may be required.

$$
\text { conversion factor }=\frac{c}{2 f_{0}}
$$

Table 4. Tuning fork conversion factors.

\begin{tabular}{|c|c|c|c||}
\hline \hline Band & $\begin{array}{c}\text { Frequency } \\
(\mathbf{G H z})\end{array}$ & Conversion Factor & $\begin{array}{c}\text { Conversion Factor } \\
\text { (Kustom Signals }{ }^{1} \text { ) }\end{array}$ \\
\hline X-band & 10.525 & 0.0318583 & 0.0318674 \\
\hline K-band & 24.150 & 0.0138844 & 0.0138844 \\
\hline Ka1-band & 33.800 & 0.0099204 & $\mathrm{NA}$ \\
\hline Ka-band & 34.700 & 0.0096631 & 0.00944528 \\
\hline Ka-band & 35.500 & 0.0094453 & \\
\hline
\end{tabular}

Example: A typical 50 mph K-band fork may have an oscillation frequency of $3652.4 \mathrm{~Hz}$. Its speed is calculated as follows:

$$
3652.4 \mathrm{~Hz} \times(0.0138844 \mathrm{mph} / \mathrm{Hz})=50.7 \mathrm{mph}
$$

\footnotetext{
${ }^{1}$ Kustom Signals, Inc. information is provided as an example with appropriate conversion factors and is not intended as an endorsement or preference.
} 
3.3 Record and report this product as the "speed" of the tuning fork to the nearest $0.01 \mathrm{mph}$ or $0.1 \mathrm{mph}$ as requested.

3.4 The tolerance of a tuning fork is determined by the manufacturer.

3.4.1 A few manufacturers (i.e., Kustom Signals, Inc.) have designed their speed guns to truncate (round-down) to the first whole mile per hour. This is done to give the benefit of fractional speeds to the motorist. Therefore, the tolerance of these tuning forks is:

$$
-0.00 \mathrm{mph} \text { to }+0.99 \mathrm{mph}
$$

CAUTION: These speed guns must be mated to their associated tuning forks. These tuning forks cannot be used interchangeably with other speed gun manufacturers. It is recommended that all tuning forks be mated to their respective manufacturer speed guns.

3.4.2 Other manufacturers have designed their speed guns to round to nearest whole mph. These tuning forks have a tolerance of:

$$
-0.50 \mathrm{mph} \text { to }+0.49 \mathrm{mph}
$$

$4 \quad$ Measurement Assurance

4.1 Duplicate the process with suitable check standards using the same transducer used to take the observations of the device under test, either the clamping type contact pickup, or the microphone and create a control chart.

4.2 Evaluate the values against the expected limits of the control charts. Plot the values to monitor changes over time. A t-test may be used to check the observed value against the accepted value.

4.3 Check standard observations are used to calculate the standard deviation of the measurement process, $s_{p}$.

5 Assignment of Uncertainty

The limits of expanded uncertainty $(U)$ include estimates of the standard uncertainty of the standard $\left(u_{s}\right)$, estimates of the standard deviation of the measurement process $\left(s_{p}\right)$, an estimate for the uncertainty for the resolution of the frequency counter $\left(u_{\text {counter }}\right)$, and an estimate for the uncertainty of the device used to record the ambient air temperature $\left(u_{\text {temp }}\right)$. These estimates are combined using the root-sum-squared method and the expanded uncertainty reported with a coverage factor $(k)$, based on degrees of freedom, to give an approximate $95 \%$ level of confidence. 
5.1 Mechanical instability of a tuning fork, which varies with manufacturer, age, physical condition, etc., is the greatest cause of error in a tuning fork measurement. This has been experimentally shown to be less than $\pm 0.01 \%$. This portion of the uncertainty is included in the standard deviation of the process $\left(s_{p}\right)$.

5.2 Temperature changes of a tuning fork will cause its frequency (and thus speed) to change in a sufficiently linear fashion with inverse correlation due to the changing modulus of elasticity with temperature. The change is approximately $-0.000132 \mathrm{mph}$ per each rated mph per $1^{\circ} \mathrm{F}$.

Example: At $70{ }^{\circ} \mathrm{F}$, a $50 \mathrm{mph}$ fork is measured to be $50.71 \mathrm{mph}$. At $10^{\circ} \mathrm{F}$, the measurement will be approximately $51.11 \mathrm{mph}$ :

$$
50.71 \mathrm{mph}+((-0.000132) \times 50 \times(10-70))=51.106 \mathrm{mph}
$$

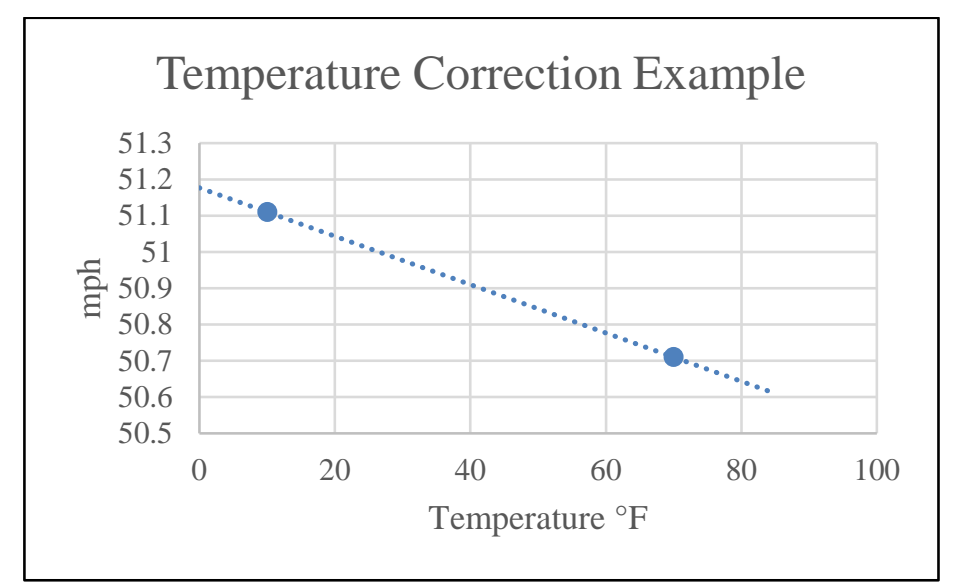

Figure 2. Temperature Correction Example.

5.3 Errors related to the broadcast signals (reference standards) are generally negligible, however may be included in the uncertainty budget $\left(u_{s}\right)$.

Table 5. Example Uncertainty Budget Table.

\begin{tabular}{||l|c|c|c||}
\hline \multicolumn{1}{|c|}{$\begin{array}{c}\text { Uncertainty Component } \\
\text { Description }\end{array}$} & Symbol & Source & $\begin{array}{c}\text { Typical } \\
\text { Distribution }\end{array}$ \\
\hline \hline $\begin{array}{l}\text { Uncertainty for the reference } \\
\text { standard }\end{array}$ & $u_{s}$ & $\begin{array}{c}\text { NIST traceable frequency } \\
\text { standard (telephone, receiver, } \\
\text { GPS clock) } \\
\text { NIST website (SP 960-12) }\end{array}$ & Rectangular \\
\hline $\begin{array}{l}\text { Standard deviation of the } \\
\text { process }\end{array}$ & $s_{p}$ & $\begin{array}{c}\text { Laboratory assessments, pooled } \\
\text { standard deviation }\end{array}$ & Normal \\
\hline $\begin{array}{l}\text { Uncertainty for the mechanical } \\
\text { instability of the tuning fork }\end{array}$ & $u_{i}$ & $\begin{array}{c}\text { Normally included in the } \\
\text { standard deviation of the } \\
\text { process }\end{array}$ & Rectangular \\
\hline $\begin{array}{l}\text { Uncertainty of the for } \\
\text { temperature effects }\end{array}$ & $u_{t}$ & $\begin{array}{c}\text { Estimates may be calculated } \\
\text { with equations in section 5.2 }\end{array}$ & Rectangular \\
\hline \hline
\end{tabular}


5.4 Typically, the expanded uncertainty of the measurement process does not exceed $\pm 0.02 \%$ plus small variations caused by laboratory temperature changes. Normally this impact is less than $0.05 \mathrm{mph}$.

\section{$6 \quad$ Certificate}

Report results as described in SOP No. 1, Preparation of Calibration Certificates. Report the tuning fork serial numbers, tuning fork speed and/or acoustic instrument oscillation frequency (if appropriate), environmental conditions during the calibrations, specifically temperature, and the calculated uncertainties.

\section{$7 \quad$ Acknowledgements and Validation}

This SOP and various iterations were developed by the States of Colorado, New Jersey, Alaska, and Virginia with collaboration and input from NIST (and NBS) staff David Allan and Michael Lombardi. This version is a consolidation of the various approaches to reference standards that are successfully being used for the calibration of tuning forks for legal applications.

Tuning fork PTs have been coordinated by Garret Brown from Alaska for laboratory Recognition and Accreditation and for validation of this procedure. 
SOP 24

\section{Standard Operating Procedure \\ for}

\section{Calibration of Stopwatches and Timing Devices}

1 Introduction

\section{$1.1 \quad$ Purpose}

This procedure is used to calibrate Type I or Type II stopwatches and timing devices used by Weights and Measures officials, industrial, technical and other interests concerned with traceable time measurements.

1.1.1 Type I: These stopwatches utilize digital, electronic circuitry to measure time intervals.

1.1.2 Type II: These stopwatches utilize analog, mechanical mechanisms to measure time intervals.

\subsection{Applicable References}

1.2.1 NIST Handbook 44, Specifications, Tolerances, And Other Technical Requirement for Weighing and Measuring Devices, Section 5.55, Timing Devices.

1.2.2 NIST Special Publication (SP) 960-12, Stopwatch and Timer Calibrations.

1.2.3 NIST Handbook 105-5: Specifications and Tolerances for Field Standard Stopwatches.

\subsubsection{NIST SP 432: NIST Time and Frequency Service.}

\subsection{Range and Scope}

Detailed measurement ranges, standards, equipment, and uncertainties for this SOP are generally compiled in a separate document in the laboratory.

\subsection{Limitations}

Limitations of this method and the applicable services that can be offered can be determined by calculating an uncertainty associated with the method that will be used to provide the comparison of time to customer devices being calibrated. The expanded uncertainty with this procedure must be less than or equal to one third $(\leq 1 / 3)$ of the tolerance per NIST Handbook 105-5 when used for legal metrology applications which is $0.02 \%$. The primary factors limiting the calibration uncertainty are related to the human reaction time, standard deviation in operation and the resolution of the stopwatch or timing devices. 


\subsection{Prerequisites}

1.5.1 Verify that the metrologist performing the calibration is trained and proficient in performing this procedure and that his/her start/stop response time is documented and available.

1.5.2 Standard reference time signals must be available that can provide suitable traceability to the International System of Units (SI). Several options may be considered as noted in section 2.3. Suitable reference standards are maintained, with traceability to the SI, by NIST.

1.5.3 Two stopwatches or timing devices with resolution of $0.01 \mathrm{~s}$ or better for determining human reaction time factors.

1.5.4 No specific environmental conditions are required for this procedure. However, calibrations should be conducted under normal laboratory conditions due to the general design of timing devices and potential temperature influences both above and below standard laboratory conditions and environmental data for temperature, barometric pressure, and relative humidity should be recorded. For most stopwatches and timing devices used in weights and measures, the influence of the human reaction time in operating the device and the resolution of the device far outweigh environmental influence factors.

1.5.5 A stopwatch support stand or lanyard that will hold a spring-driven Type II stopwatch or timing device in a vertical position for a repeat calibration.

$2 \quad$ Methodology

\subsection{Summary}

This procedure uses a NIST traceable audio time signal from a telephone (not cell phone) or shortwave receiver, or a time signal from the GPS satellites as the reference standard. The unknown stopwatch or timing device is started to coincide with the respective signal or indication for the standard, allowed to run a calculated interval, and then stopped to coincide with an additional signal from the reference standard. The correction, $C_{x n}$, for each run is calculated. 
2.2 Caution: Calibration methods do not require opening the case of the stopwatch or timing device. A stopwatch or timing device should never be disassembled to measure the time base frequency by making a direct electrical connection.

2.3 Standards with suitable traceability and resolution must be available and may include one of the following.

2.3.1 An operational shortwave receiver to receive the broadcast timing signal on one of the frequencies listed in Table 2, or;

2.3.2 A land line telephone to call one of the numbers listed in Table 2, to receive the broadcast timing signal; or

2.3.3 A GPS master clock. Verify that the GPS Master Clock is locked to GPS signals. In order for a GPS display to be used as a reference, there must be an indicator on the unit that shows whether the display is currently locked to the GPS signal, or is in "coast" mode. If the receiver is in "coast" mode, it should not be used as a calibration reference.

\subsection{Symbols Used in this Procedure}

Table 1. Symbols used in the procedure.

\begin{tabular}{|c|l||}
\hline Symbol & \multicolumn{1}{c|}{ Description } \\
\hline \hline$A B S$ & Absolute value, mathematical function \\
\hline$C_{x n}$ & $\begin{array}{l}\text { Correction of the unknown stopwatch or timing device } \\
\text { for each run }\end{array}$ \\
\hline$R$ & Amount of rollover time \\
\hline$X$ & Unknown stopwatch or timing device being calibrated \\
\hline$T_{s n}$ & Tolerance \\
\hline$T_{x}$ & $\begin{array}{l}\text { Observed elapsed time of the unknown stopwatch or } \\
\text { timing device }\end{array}$ \\
\hline$U T C_{1}$ & Start of calibration in Coordinated Universal Time \\
\hline$U T C_{2}$ & End of calibration in Coordinated Universal Time \\
\hline $\begin{array}{l}\text { a The point where the elapsed time exceeds the maximum indication of time } \\
\text { provided by the stopwatch. At the rollover point, the stopwatch automatically starts } \\
\text { again at zero or shuts itself off. The user of the stopwatch must account for each } \\
\text { rollover to correctly measure long elapsed times. }\end{array}$ \\
\hline
\end{tabular}




\subsection{Preliminary Procedure}

2.5.1 Ensure proper preparation and operation of the stopwatch or timing device to be calibrated. Batteries should be fresh, if applicable. The mainspring on the device must be fully wound, if applicable. The metrologist should familiarize themselves with the operation of each button (e.g., start, stop, reset) on the stopwatch or timing device. The stopwatch or timing device should be operating smoothly and freely.

2.5.2 Determine an appropriate calibration interval, e.g., 1 hour, 3 hour, 24 hour

Ensure that a suitable calibration interval is used by using a one to five ratio of the estimated uncertainty to the applicable tolerance. The calibration interval may also require assessment of the type of stopwatch or timing device being calibrated to ensure it will continue operation for the required interval and to ensure it has sufficient resolution.

\subsubsection{Example tolerance calculation for calibration intervals.}

Tolerance: $3 \mathrm{~h} \times \frac{60 \mathrm{~min}}{\mathrm{~h}} \times \frac{60 \mathrm{~s}}{\min } \times 0.02 \%=2.16 \mathrm{~s}$ truncated to $2.1 \mathrm{~s} \quad$ Eqn. (1)

For this 3 hour example, the uncertainty must be less than 0.42 seconds (and a $1 \mathrm{~s}$ resolution device is not suitable).

2.5.2.2 Uncertainty to tolerance ratio calculation.

$$
\text { Uncertainty }<\frac{2.1 \mathrm{~s}}{5}
$$

A 1 hour calibration interval will require an uncertainty of less than 0.14 seconds. The uncertainty must be less than 3.4 seconds for a 24-hour interval and a $1 \mathrm{~s}$ resolution device may be able to meet this requirement.

\subsubsection{Establish a Traceable Time Signal}

The same signal source must be used for both the start and stop times. 
Table 2. Reference calibration sources.

\begin{tabular}{|c|c|c|c|c|}
\hline Service & Location & $\begin{array}{l}\text { Telephone } \\
\text { Number }\end{array}$ & $\begin{array}{c}\text { Radio Call } \\
\text { Letters }\end{array}$ & $\begin{array}{l}\text { Broadcast } \\
\text { Frequencies }\end{array}$ \\
\hline NIST & Ft. Collins, CO & (303) 499-7111 & WWV & $\begin{array}{l}2.5 \mathrm{MHz} \\
5 \mathrm{MHz} \\
10 \mathrm{MHz} \\
15 \mathrm{MHz} \\
20 \mathrm{MHz}\end{array}$ \\
\hline NIST & Kauai, HI & (808) 335-4363 & WWVH & $\begin{array}{l}2.5 \mathrm{MHz} \\
5 \mathrm{MHz} \\
10 \mathrm{MHz} \\
15 \mathrm{MHz}\end{array}$ \\
\hline $\begin{array}{l}\text { U.S. Naval } \\
\text { Observatory (USNO) }\end{array}$ & District of Columbia & $\begin{array}{l}\text { (202) 662-1401 } \\
\text { (202) 762-1069 }\end{array}$ & ---- & ---- \\
\hline USNO & Colorado Springs, CO & (719) 567-6742 & ----- & (---- \\
\hline $\begin{array}{l}\text { National } \\
\text { Research Council } \\
\text { (NRC) }\end{array}$ & $\begin{array}{l}\text { Ottawa, Ontario, } \\
\text { Canada }\end{array}$ & $\begin{array}{l}\text { (613) 745-1576 } \\
\text { (English) } \\
\text { (613) 745-9426 } \\
\text { (French) }\end{array}$ & $\mathrm{CHU}$ & $\begin{array}{l}3.33 \mathrm{MHz} \\
7.850 \mathrm{MHz} \\
14.67 \mathrm{MHz}\end{array}$ \\
\hline
\end{tabular}

Note: Do not use local "time \& temperature" telephone services, cell phones, or a time display from a radiocontrolled clock or a website as these sources are not considered traceable.

\subsection{Obtain Human Response Time Bias Data}

To determine the start/stop response of the metrologist, use a shortwave receiver for continuous broadcast of the timing signals (Note: a telephone can be used but there is a time limit of three minutes for each call). Hold a stopwatch in each hand and start both stopwatches simultaneously on a minute tone and then stop both simultaneously on the very next minute tone. Record the bias from the interval for each stopwatch each time a calibration is performed and add results to the laboratory response time control chart designated for that staff member. If the start time for each watch is reset, the start time, $T_{x 1}$ will be zero in as shown in the Eqn. 7. See Section 4.1 to establish repeatability data and measurement assurance data.

\subsection{Measurement Procedure}

2.7.1 Connect to the selected time signal (note that a telephone signal will be limited and will not continue to broadcast during the calibration interval).

2.7.2 Start the two laboratory stopwatches used for determining the metrologist start/stop time response on a minute tone and stop on the very next minute tone. Record the bias and plot on the Human Response Time control chart for that metrologist. 
2.7.3 Start the unknown timer at a minute tone and record the reference UTC time as $U T C_{1}$.

2.7.4 At or after the previously determined calibration interval, connect to the time signal again if needed, then stop the unknown timer at a minute tone and record the UTC time as $U_{T} C_{2}$

2.7.5 Calculate elapsed time of the standard for the first run, $T_{s 1}$, using Equation 3.

2.7.6 Calculate the unknown error for the first run, $C_{x 1}$, by comparing the elapsed time of the standard, $T_{s 1}$, to the observed elapsed time on the unknown timer, $T_{x}$, using Equation 4 . Be sure to account for any rollover, $R$, in the unknown timer.

2.7.7 Calculate and determine the tolerance status using Equation 5.

2.7.8 If the unknown timer appears to be in tolerance switch hands used to calibrate each timer and repeat steps 2.7.3 through 2.7.7 to obtain the unknown error for run two, $C_{x 2}$. Switching hands in this step is performed to eliminate potential errors with the human response time.

2.7.9 Calculate and report the mean correction for the unknown, $\overline{C_{x}}$, using Equation 6.

2.7.10 NOTE: Spring driven Type II stopwatches shall be calibrated in two different orientations; horizontal (with dial face up), and vertical (with crown up). The main spring shall be fully wound before each run.

3 Calculations (Measurement Equations)

3.1 Calculate the Elapsed Time for each Run for the Standard, $T_{s 1}$ and $T_{s 2}$ using Eqn. 3.

$$
T_{\text {sn }}=U T C_{1}-U T C_{2}
$$

3.2 Calculate the Error for each Run for the Unknown, $\mathrm{C}_{x 1}$ and $\mathrm{C}_{x 2}$ using Eqn. 4 and add applicable Rollover, $R$.

$$
C_{x n}=\left(T_{x}+R\right)-T_{s n}
$$

3.3 Calculate and Determine the Tolerance Status for each Run where the values pass using Eqn. 5 when the absolute value of the error plus the expanded uncertainty is less than the tolerance for the elapsed time (see Section 6.1 also).

$$
\text { Pass if: }\left|C_{x n}+U_{x}\right| \leq \text { Tolerance for } T_{s n}
$$


3.4 Calculate and Report the Mean Correction for the Unknown using Eqn. 6.

$$
\overline{C_{x}}=\frac{\left(C_{x 1}+C_{x 2}\right)}{2}
$$

3.5 Calculate the observed human response time bias using Eqn. 7.

$$
\text { Bias }=\left(T_{x 2}-T_{x 1}\right)-\left(U T C_{2}-U T C_{1}\right) \quad \text { Eqn. (7) }
$$

$4 \quad$ Measurement Assurance

4.1 Determine the human response time and bias components of the measurement process by conducting the human response time assessment as described in Section 2.6 for at least 10 cycles, switching the stopwatches into opposite hands, recording data for every event. Start a control chart for the response time for each metrologist who will be conducting timing calibrations. One additional cycle will be conducted for each stopwatch measurement and plotted on the control chart for all future calibrations. It is recommended that all laboratory staff use the same two stopwatches to establish bias and ensure that any differences detected are NOT due to differences in the accuracy of the stopwatches used. The bias is calculated using Eqn. 7.

An example of the initial chart data for the stopwatch data might look like this:

- Left Bias (watch 1) Right Bias (watch 2)

- Left Bias (watch 2) Right Bias (watch 1)

- Left Bias (watch 1) Right Bias (watch 2)

- Left Bias (watch 2) Right Bias (watch 1)

- Left Bias (watch 1) Right Bias (watch 2)

- Left Bias (watch 2) Right Bias (watch 1)

- Left Bias (watch 1) Right Bias (watch 2)

- Left Bias (watch 2) Right Bias (watch 1)

- Left Bias (watch 1) Right Bias (watch 2)

- Left Bias (watch 2) Right Bias (watch 1)

4.1.1 Observed differences in reaction time between the metrologist reaction and a reference signal are used to determine a typical bias for each metrologist.

4.1.2 Two response times are used to calculate a standard deviation to be plotted on a standard deviation chart. Response standard deviations are pooled to determine an accepted standard deviation. The observed repeatability of each calibration may be compared to the accepted standard deviation using an F-test.

4.1.3 The repeatability data for the calibration is evaluated to ensure it is within acceptable limits. If the repeatability from the two runs is outside 
the control limits, conduct a root cause analysis or troubleshoot the source of the problems before repeating the calibration or reporting calibration results.

4.2 The measurement process may be duplicated with a suitable check standard(s) to replicate the measurement process. However, one person may not able to actuate a standard, stopwatch or timing device being calibrated, and a check standard all at the same time and will need to offset the times at the next designated signal. Duplicate calibrations may be needed to calibrate check standards. Evaluate the check standard immediately after the runs to ensure the values are in control. Suitable check standards may be used to determine values for section 4.1. Differences in variability of Type I and Type II devices and associated resolutions (or absence of differences) will need to be verified. The check standard data will incorporate repeatability, bias, and resolution influence data; therefore, the laboratory should consider what uncertainty components could be double counted resulting in overestimated uncertainties.

Examples of uncertainty budgets and sample data are presented in NIST SP 960-12, Tables 8, 9, 10, and 11. The uncertainty is calculated according to NISTIR 6969, SOP 29 to ensure compliance with the Guide to the Expression of Uncertainty in Measurement.

\subsection{Uncertainty for the Standard, $u_{s}$}

Determine the uncertainty for the standard based on the type of standard that is used for the calibration. See pages 31 and 32 in NIST SP 960-12. (This uncertainty is usually nearly negligible for telephone, radio, and GPS standards compared to the human reaction time factors.)

5.2 Uncertainty for the human reaction time repeatability, standard deviation of the process, $s_{p}$

The standard deviation of two replicate runs are tracked over time and used to determine a pooled standard deviation associated with the repeatability of the measurement process.

5.3 Uncertainty for the human reaction time bias, $u_{b}$

A comparison between the absolute time values from the standard source and the check standard(s) are used to calculate a bias for each metrologist. The bias is calculated for at least 10 runs and is treated as a rectangular distribution.

5.4 Uncertainty for the resolution of the timing device, $u_{r}$

The resolution of the instrument is treated as a rectangular distribution whether digital or analog (as analog timing devices also use discrete $1 \mathrm{~s}$ intervals). 
Table 3. Example Uncertainty Budget Table.

\begin{tabular}{||l|c|c|c||}
\hline \multicolumn{1}{|c|}{$\begin{array}{c}\text { Uncertainty Component } \\
\text { Description }\end{array}$} & Symbol & Source & $\begin{array}{c}\text { Typical } \\
\text { Distribution }\end{array}$ \\
\hline \hline $\begin{array}{l}\text { Uncertainty for the reference } \\
\text { standard }\end{array}$ & $u_{s}$ & $\begin{array}{c}\text { NIST traceable time standard } \\
\text { (telephone, receiver, GPS clock) } \\
\text { NIST website (SP 960-12) }\end{array}$ & Rectangular \\
\hline $\begin{array}{l}\text { Standard deviation of the } \\
\text { process, human reaction time } \\
\text { repeatability }\end{array}$ & $s_{p}$ & $\begin{array}{c}\text { Laboratory assessments, pooled } \\
\text { standard deviation }\end{array}$ & Normal \\
\hline $\begin{array}{l}\text { Uncertainty of the human } \\
\text { reaction time bias }\end{array}$ & $u_{b}$ & $\begin{array}{c}\text { Comparison of metrologist to } \\
\text { reference signal }\end{array}$ & Rectangular \\
\hline $\begin{array}{l}\text { Uncertainty of the stopwatch or } \\
\text { timing device resolution }\end{array}$ & $u_{r}$ & Resolution of the instrument & Rectangular \\
\hline
\end{tabular}

5.5 Calculate the combined uncertainty, $u_{c}$, and the expanded uncertainty for the unknown stopwatch or timing device, $U_{x}$, using the root sum square method described in NISTIR 6969, SOP 29 and use the appropriate effective degrees of freedom to determine a coverage factor to provide an approximate $95 \%$ confidence interval.

5.6 Evaluate the uncertainty. Review the conformity assessment requirements in Section 6. to evaluate the adequacy of the uncertainty. A longer time interval for the calibration may be required, especially with timing devices with larger resolutions.

5.7 Report the calculated uncertainty to two significant digits according to SOP 29 and issue a suitable uncertainty statement.

$6 \quad$ Certificate

6.1 Report results as described in SOP No. 1, Preparation of Calibration Certificates. Report the measured time results (and the deviation of time values from the nominal time calibrated if applicable), the duration of the calibration conducted, and calculated uncertainties.

\subsection{Conformity Assessment}

A stopwatch is considered to be within tolerance when the absolute value of its error plus its uncertainty is less than or equal to the tolerance established in NIST Handbook $105-5$. The tolerance is $0.02 \%$ of the calibration interval with values truncated to the device resolution as needed. Provide a compliance/conformity statement on the calibration certificate if the stopwatch or timing device will be used for a weights and measures application. 
6.2.1 Example tolerance evaluation for a 3-hour interval on a device with 0.01 s resolution:

$$
\begin{array}{cc}
\text { Tolerance }=3 \mathrm{~h} \times \frac{60 \mathrm{~min}}{\mathrm{~h}} \times \frac{60 \mathrm{~s}}{\min } \times 0.02 \%=2.16 \mathrm{~s} & \text { Eqn. (8) } \\
C_{x}+U_{x}=0.25 \mathrm{~s}+0.35 \mathrm{~s}=0.60 \mathrm{~s} & \text { Eqn. (9) }
\end{array}
$$

The value of $0.60 \mathrm{~s}$ is less than $2.16 \mathrm{~s}$, thus is considered in tolerance.

6.2.2 Example tolerance evaluation for a 24-hour interval on a device with $1 \mathrm{~s}$ resolution, truncated to the nearest second:

$$
\begin{array}{cc}
\text { Tolerance }=24 \mathrm{~h} \times \frac{60 \mathrm{~min}}{\mathrm{~h}} \times \frac{60 \mathrm{~s}}{\min } \times 0.02 \%=17.28 \mathrm{~s} \text {, or } 17 \mathrm{~s} & \text { Eqn. (10) } \\
C_{x}+U_{x}=15.0 \mathrm{~s}+3.5 \mathrm{~s}=18.5 \mathrm{~s} & \text { Eqn. (11) }
\end{array}
$$

The value of $18.5 \mathrm{~s}$ is greater than $17 \mathrm{~s}$ thus is out of tolerance and would be rejected.

Inputs to this procedure were submitted with procedures from the following State laboratories: Washington, Pennsylvania, California, and New York. The original version of SOP 24 was developed by Dan Wright and reviewed by SP 960-12 authors Jeff Gust and Mike Lombardi for suitability and compliance to requirements in SP 960-12 and good measurement practices. Modifications were made in Pennsylvania, California, and New York to introduce specific standards, applications, and recording approaches used in their laboratories. Users applying methods for weights and measures must make sure to use requirements in NIST Handbook 44 as the over/under-registration limits in SP 960-12 are reversed.

Suitability and reproducibility of this procedure was successfully demonstrated through proficiency tests (PT) conducted among the following laboratories in report NAT-16-FT-M01 (as coded by OWM) for a 3-hour calibration interval who used SOP 24 as developed or modified in their laboratories: Pennsylvania, Troemner, New Jersey, New York, Connecticut, Ohio, California, Washington, and Hawaii; the highest normalized error $\left(E_{n}\right)$ among these laboratories was 0.22 . All precision assessments, $P_{n}$, were acceptable. Uncertainties varied for these laboratories from $0.068 \mathrm{~s}$ to $0.48 \mathrm{~s}$. All participant values for the 3-hour calibration were within one third of the Handbook 44 tolerance that was specified as $1.875 \mathrm{~s}(0.017 \%)$. Note that a tolerance of $0.02 \%$ is specified in NIST Handbook 105-5. 
SOP 27

\section{Standard Operating Procedure \\ for}

\section{Railroad Test Cars Using a Master Track Scale}

1 Introduction

\subsection{Purpose.}

This Standard Operation Procedure (SOP) describes the procedure to be followed for the calibration of railroad test cars on master track scales calibrated (certified) by the U.S. Department of Agriculture (USDA). By necessity, the SOP has been generalized to accommodate the variety of designs of master scales in the United States. The maximum railroad test car load is determined by the scale capacity and available length of track on each master track scale. The accuracy and precision of the calibration is determined by the reported values for each master track scale as part of the USDA railroad scale testing program, the proficiency and experience of the operator, and any additional control information maintained.

1.2 Detailed measurement ranges, standards, equipment, and uncertainties for this SOP are generally compiled in a separate document in the laboratory.

1.3 Limitations: The maximum railroad test car load shall not exceed the maximum calibration point listed on the master track scale calibration certificate or the nominal capacity of the master track scale.

\subsection{Prerequisites}

1.4.1 The master scale must have an up-to-date calibration along with a scale correction for the load being tested. The calibration must have demonstrated metrological traceability to the international system of units (SI), which may be to the SI through a National Metrology Institute such as NIST.

1.4.2 Access to the scale must be limited to authorized personnel only. If the master scale is owned by the railroad or other private entity, security must be maintained and controlled; registered keys to the facility must be provided.

1.4.3 Regularly scheduled calibration of all railway track scales is required because the scale is used as a secondary standard. If a jurisdiction can supply certified test weights and appropriate delivery systems to conduct a substitution test, then the scale may be used as a comparison scale. 
1.4.4 The scale, process, and standards must be evaluated to ensure that the combined standard uncertainties for the intended level of calibration are sufficiently small.

1.4.5 When mass standards are used with substitution methods, ensure the availability of suitable working standards or recently calibrated (and unused) field standards (e.g., NIST Class F, OIML Class $\mathrm{M}_{1}$ ) in quantities up to the capacity of the railroad test car that will be calibrated. All standards must have known conventional mass values with valid metrological traceability to the SI, which may be through laboratory working standards to the National Institute of Standards and Technology. In the case of substitution measurements, refer to NISTIR $6969^{1}$, SOP 4, Double Substitution.

1.4.6 The metrologist or specialist must be experienced in the operation of the master scale and have adequate means to deliver the test car to and from the scale. The metrologist is reminded of the importance of evaluating potential safety hazards prior to a calibration and taking adequate precautions to avoid personal injury or damage to the scale or the railroad test car. If the master scale is under the control of the railroad and/or located on railroad property, the work will need to be coordinated with railroad personnel.

1.4.7 Environmental conditions must be suitable for mass calibrations and within the recommended limits noted in Table 1. Equilibration times for railroad test cars are noted in Table 2. Deviation from these limits is permissible but may need to include additional corrections and uncertainty components due to possible convection currents. Railroad test cars that do not completely fit within the enclosed structure, allowing the doors to be closed, must be calibrated only when external environmental conditions are acceptable. The scale should be protected from the effects of wind and adverse weather. In some installations, drafts may still be prevalent, applying force to the scale. Every effort should be taken to eliminate the effects of air movement.

Table 1. Recommended environmental conditions.

\begin{tabular}{|c|c|}
\hline Temperature & Relative Humidity \\
\hline $18{ }^{\circ} \mathrm{C}$ to $27^{\circ} \mathrm{C}$ & $20 \%$ to $80 \%$ \\
\hline
\end{tabular}

1.4.8 Railroad test cars must be properly cleaned and painted and all repairs completed (as needed) prior to calibration. See section 2.3.3. for inspection requirements.

\footnotetext{
${ }^{1}$ NISTIR 6969, Selected Laboratory and Measurement Practices, and Procedures to Support Basic Mass Calibrations.
} 
1.4.9 Railroad test cars must be completely dry, with no ice or moisture on the surface or under carriage of the car.

Experience has shown that a light coating of frost can cause errors in excess of the tolerance for the car. In heated facilities, the test car must be allowed sufficient time to warm to prevent condensation.

Table 2. Recommended stabilization times.

\begin{tabular}{|c|c|c|}
\hline $\begin{array}{c}\text { Temperature Range } \\
22{ }^{\circ} \mathrm{C} \text { (facility) }\end{array}$ & $\begin{array}{c}\text { Temperature Range } \\
72^{\circ} \mathrm{F} \text { (facility) }\end{array}$ & $\begin{array}{c}\text { Minimum } \\
\text { Equilibration Time* }\end{array}$ \\
\hline $\pm 5^{\circ} \mathrm{C}, 17^{\circ} \mathrm{C}$ to $28^{\circ} \mathrm{C}$ & $\pm 10^{\circ} \mathrm{F}, 62^{\circ} \mathrm{F}$ to $82^{\circ} \mathrm{F}$ & 4 hours \\
\hline$<17^{\circ} \mathrm{C}$ and $>28^{\circ} \mathrm{C}$ & $<62{ }^{\circ} \mathrm{F}$ and $>82^{\circ} \mathrm{F}$ & 24 hours/overnight \\
\hline
\end{tabular}

1.4.10 Railroad test cars that repetitively demonstrate excessive "as found" out-of-tolerance conditions from the previous calibration date, may be required to be submitted on a more frequent basis; with every consideration being given to determine the cause of the variability.

1.4.11 Railroad test cars with unacceptable ballast; i.e., cement, pulverized lead, or other materials that absorb water or oxidize excessively, should be documented as to their instability. Repetitive tests demonstrating instability will warrant removal of the test car from service until the problem is corrected.

1.4.12 Stenciled weight of railroad test cars under USDA jurisdiction are required to be in 1,000 lb increments. Decals may be used for nonUSDA railroad test cars, which may also be set to the nearest $100 \mathrm{lb}$ increments.

$2 \quad$ Methodology

\subsection{Summary}

A railroad test car is calibrated by taking direct readings from the USDA calibrated railroad master track scale. The master track scale is calibrated by using calibrated $10000 \mathrm{lb}$ mass standards and $10000 \mathrm{lb}$ weight cart that are maintained with traceability to the SI, and calibrated in a recognized ${ }^{2}$ facility in Clearing, Illinois.

\footnotetext{
${ }^{2}$ NIST Office of Weights and Measures, Handbook 143, Program Handbook provides recognition of compliance to program requirements associated with ISO/IEC 17025 and suitable evidence of metrological traceability.
} 


\subsection{Equipment / Apparatus}

2.2.1 A track scale in good operating condition, with a current calibration certificate as noted in prerequisites.

2.2.2 Barometer (if available), thermometer, and hygrometer with sufficiently small resolution, stability, and uncertainty (See NISTIR $6969^{3}$, SOP 2) to record the monitored environmental conditions at the $1 \%$ of air density level. Buoyancy corrections are not performed in this procedure; however, environmental data is critical to demonstrate environmental stability during the calibration. ${ }^{4}$

2.2.3 Correction or error weights adjusted to within NIST Class $\mathrm{F}^{5}$ tolerances with current calibration certificate(s).

\subsubsection{Hand tools:}

\subsubsection{Wrenches;}

\subsubsection{Screw driver;}

\subsubsection{Wire cutters; and}

2.2.4.4 Solvent to free rusty locks, as needed.

2.2.5 Means to safely move the railroad test car.

2.2.6 Operational knowledge of railroad test cars including the braking system and operating controls is required. Only qualified personnel should operate and inspect the test car. Verification that the brakes are operative prior to movement of the vehicle is imperative.

2.2.7 Suitable adjustment material must be available for placement in the adjusting compartments.

2.2.8 Check list or inspection work sheet.

2.2.9 For reasons of safety and the observance of unstable operations, two people are recommended for performing the calibration.

\footnotetext{
${ }^{3}$ NISTIR 6969, Selected Laboratory and Measurement Practices, and Procedures to Support Basic Mass Calibrations.

${ }^{4}$ For most mass calibrations, the barometer, thermometer, and hygrometer are used to determine the air density at the time of the measurement. The air density is used to make an air buoyancy correction. The limits specified are recommended for high precision calibration. For this calibration, buoyancy corrections are not performed.

${ }^{5}$ NIST Handbook 105-1, 1990, Specifications and Tolerances for Field Standard Weights (NIST Class F).
} 


\subsection{Pre-calibration Inspections}

\subsubsection{Inspect the Master Scale}

2.3.1.1 Inspect the scale deck for wear and check for binds between the weigh rail and the approach rail.

2.3.1.2 Measure the gap between the weigh rail and the approach rail. If this distance is less than $1 / 8$ in or more than $3 / 8$ in based on requirements in the American Association of Railroads Handbook, a service technician must make adjustments prior to the calibration.

2.3.1.3 Inspect the scale pit for cleanliness and dryness.

2.3.1.4 Inspect the weigh beam, poise, butt connections, and counterpoise tip loop connections. While performing this inspection, put the blade edge of a screwdriver between the weigh beam and the side of the clevis at the pivot point, adjusting as necessary so there is equal distance on both sides between the clevis and the beam.

2.3.1.5 If using ratio weights, butt weights, or tip weights, confirm the ratio of the beam. This procedure can be useful to establish the as-found error. Railroad test cars that have been recently reconditioned may require several hundred pounds of adjustment material and correction to return them to nominal mass. Using ratio kits can reduce the amount of weight handling.

\subsubsection{Inspect the Master Scale House}

2.3.2.1 Note the following conditions and take action as warranted:

- Accumulated dirt or debris;

- Environmental conditions that may adversely affect performance;

- No load sensitivity: out of specification condition, look for physical bind, rodent or snake activity;

- "As found" balance condition;

- Evidence of tampering or unauthorized entrance; and

- Unstable electronic indications.

\subsubsection{Inspect the Railroad Test Car}

2.3.3.1 Determine the type of railroad test car (see Appendix A).

2.3.3.2 Note and record the stenciled mass value. 
2.3.3.3 Visually inspect the railroad test car.

Check for damage, obvious loose parts; or, have a qualified railroad employee inspect the railroad test car. Assess the cleanliness of the railroad test car and determine if steam cleaning or painting is required prior to calibration. Note any major leaks or accumulation of oil, grease, dirt, trash, or unnecessary cargo.

2.3.3.4 Check any available operation and maintenance records; note recent derailments, repairs or incidents that could affect the calibration of the railroad test car.

Note in particular:

- Brake shoes;

- Spring hangers;

- Grab irons;

- Padlocks in place;

- Air hoses in place;

- Hand brake working status;

- Pedestal bolts;

- Retaining blocks;

- Spring condition; and

- General condition.

2.3.3.5 For, self-propelled cars, inspect the following:

- Oil level in engine;

- Fluid level in hydraulic oil reservoir, assuring that the level is within operational range;

- Motor fuel levels, removing extra gas tanks not tagged or marked as being part of the car's calibrated weight; and

- $\quad$ All fluid systems for leaks. 
2.3.3.6 Check security seals, if present, for tampering or unauthorized entry to sealed compartments.

2.3.3.7 An inventory list should be securely posted in a conspicuous place to identify extraneous equipment that is to remain in the test car as part of the calibrated value. Items not on the list must be removed prior to calibration. Note: If there is a history of unauthorized repairs, permanently stamp or color code couplers, drawbars or other replaceable equipment, and note these conditions on the calibration certificate.

2.4 Calibration Procedure (Refer to NISTIR 6969, GMP 1, Reading Turning Points on an Equal Arm Balance if needed for beam scale readings.)

\subsubsection{Zero balance the railroad track scale.}

Set the scale with no load, no drop-weights or counterpoise weights, and the sliding poise set at $50.0 \mathrm{lb}$. If there is no poise, a $50 \mathrm{lb}$ calibrated weight may be balanced on the deck of the scale. (If the test car has been recently reconditioned, a larger amount of test weight may be balanced in.) This is the reference indication, $R_{I}$, for all measurements on the scale during the calibration. Arrest the beam, release and repeat the reading to show repeatability and evidence of correct scale operation prior to use in calibrating the railroad test car.

2.4.2 Apply the drop-weights or counterpoise weights to the beam in an amount appropriate for the size of the test car to be calibrated. (i.e., $100000 \mathrm{lb}, 80000 \mathrm{lb}$ ). Adjust the amount of drop or counterpoise weights until equilibrium is reached.

2.4.3 Position the test car on the center of the scale, taking note of the position markings on the rail if so provided. These markings are noted on the Master Scale calibration report and provide for corrected values at the various markings. Record scale indication as the railroad test car observation, $S_{I}$.

2.4.4 Arrest the beam. Release and repeat reading. Record observations.

2.4.5 Adjust the test car by adding or removing stable, metal adjusting material (as needed).

2.4.6 Remove the test car, recheck the reference indication, noting any drift. Arrest, release and repeat. Record observations.

2.4.7 Reposition the test car on the center of the scale and move the sliding poise to attain equilibrium of the beam. This scale indication, $S_{I}$, determines the "as left" error. Arrest, release, and repeat. Record observations. 
2.4.8 Remove the test car and recheck the reference indication and record observations, again, noting any drift. Arrest, release, and repeat. Record observation.

\subsection{Marking}

2.5.1 Stencil the nominal value of the railroad test car and the date and location of calibration. Test cars under USDA jurisdiction are stenciled in 1,000 lb increments.

2.5.2 The metrologist may exercise discretion in marking or stamping removable or replacement components, such as drawbars or couplers.

3 Calculations (Measurement Equations)

Calculations. The calibrated scale is used as a secondary standard and the average of replicate mass values is used to assign the mass to the railroad test car. The scale indications, $S_{I}$, and the reference point indications, $R_{I}$ provide the observed conventional mass difference. The scale corrections, $S_{\text {corr }}$, is subtracted from the observed difference to provide "as found" and/or "as left" conventional mass values. Where replicate measurements are made, the mean conventional mass is calculated and reported.

3.1 Calculate the conventional mass, $C M_{x}$.

$$
C M_{x}=\left(S_{I}-R_{I}\right)-S_{c o r r}
$$

3.2 Calculate the mean conventional mass, $\overline{C M_{x}}$.

$$
\overline{C M_{x}}=\frac{C M_{x 1}+C M_{x 2}}{2}
$$

NOTE: The $S_{\text {corr }}$ needs to be subtracted whether the scale correction is positive or negative. For example, if the master scale reports lists a correction that is positive, this indicates that the scale is weighing heavy, and when negative it indicates that the scale is weighing light - as a negative scale reading correction. That means when you have a positive value for the scale correction it needs to be subtracted from the reading to determine the actual conventional mass value.

\section{$4 \quad$ Measurement Assurance}

It is not practical to duplicate this calibration process with a check standard. Replicating the measurement process is encouraged. The procedure calls for repeated measurements, in which case a standard deviation chart may be used for measurement assurance. Measurement assurance of the scale operation is obtained through scale arrestments and verification of repeated scale reference readings for each weighing. If SOP 4 is used, replicate measurements will provide estimates of standard deviation that may be pooled if appropriate following techniques in NISTIR 6969, Section 8. 


\section{$5 \quad$ Assignment of Uncertainty}

The limits of expanded uncertainty, $U$, include estimates of the standard uncertainty of the mass standards used, us, estimates of the standard deviation of the measurement process, $s_{p}$, and estimates of the effect of other components associated with this procedure. These estimates should be combined using the root-sum-squared method (RSS), and the expanded uncertainty, $U$, reported with a coverage factor to be determined based on the degrees of freedom, which if large enough will be 2, $(k=2)$, to give an approximate 95 percent level of confidence. See NISTIR $6969^{6}$, SOP 29 for the complete standard operating procedure for calculating the uncertainty.

\subsection{Uncertainty for the master track scale, $u_{M S}$.}

Calculate the average uncertainty for the master scale at the calibrated nominal mass to be used for the calibration of the railroad test car from the USDA calibration certificate. The USDA calibration certificates give errors for positions at each nominal value (and for sensitivity response) to be used during the calibration; however each point does not contain uncertainties as the average value is considered for applications.

5.2 Uncertainty for correction weights, tip or butt weights, or tare weights, $u_{s}$.

Obtain uncertainties for any correction or tare weights from their respective calibration certificates.

5.3 Uncertainties for the measurement process and master track scale in use.

\subsubsection{Standard deviation of the process}

Calculate the standard deviation of replicate measurements or use the values for repeatability from the sensitivity response and zero shift observations.

\subsubsection{Sensitivity Response (or Repeatability)}

Obtain the sensitivity response value from the USDA calibration certificate for the master track scale.

\subsubsection{Zero Shift}

Record observations during the calibration to determine the average shift from the established reference point.

\footnotetext{
${ }^{6}$ NISTIR 6969, Selected Laboratory and Measurement Practices, and Procedures to Support Basic Mass Calibrations.
} 
Table 3. Example Uncertainty Budget Table.

\begin{tabular}{||c|c|c|c||}
\hline \multicolumn{1}{|c|}{$\begin{array}{c}\text { Uncertainty Component } \\
\text { Description }\end{array}$} & Symbol & Source & $\begin{array}{c}\text { Typical } \\
\text { Distribution }\end{array}$ \\
\hline \hline $\begin{array}{l}\text { Uncertainty of the master scale } \\
\text { calibration }\end{array}$ & $u_{M S}$ & USDA calibration certificate & $\begin{array}{c}\text { Normal divided by } \\
\text { the coverage factor }\end{array}$ \\
\hline $\begin{array}{l}\text { Uncertainty of correction and } \\
\text { tare weights }\end{array}$ & $u_{s}$ & Calibration certificate & $\begin{array}{c}\text { Normal divided by } \\
\text { the coverage factor }\end{array}$ \\
\hline $\begin{array}{l}\text { Standard deviation of the } \\
\text { process }\end{array}$ & $s_{p}$ & $\begin{array}{c}\text { Calculated from repeated } \\
\text { measurements }\end{array}$ & Normal \\
\hline Sensitivity response & $s_{r}$ & $\begin{array}{c}\text { One half of the USDA } \\
\text { calibration certificate reported } \\
\text { value }\end{array}$ & Rectangular \\
\hline Zero shift & $u_{z}$ & Observed data & Rectangular \\
\hline
\end{tabular}

5.4 Calculate the combined uncertainty using standard root sum square methods and expand the uncertainty with a coverage factor that is associated with appropriate degrees of freedom. Values for repeatability of similar size railroad test cars may be pooled using techniques provided in NISTIR 6969, Section 8.

5.5 Evaluation, Adjustment to Nominal, and Conformity Assessment

According to the Association of American Railroads Handbook, All test weight railroad cars are required to be maintained accurately to their designed or nominal weight values. For this purpose, each car weight shall be corrected as close to zero error and practical and certified within Class F tolerances as often as may be required. Railroad test cars should be adjusted to nominal conventional mass values (zero error) during calibration and must be maintained for use within $0.02 \%$ of the nominal mass. The expanded $(k=2)$ combined uncertainty of the calibration must be less than one-third of the tolerance $(0.0067 \%$ of the nominal mass).

\subsection{Draft an Appropriate Uncertainty Statement}

The uncertainty reported is the root sum square of the standard uncertainty of the standard, the standard deviation of the process, and the uncertainty associated with the buoyancy corrections, multiplied by a coverage factor of 2 $(k=2)$ for an approximate $95 \%$ confidence interval. Factors not considered in the evaluation: air buoyancy, magnetism, environmental variation.

Note: Where inadequate degrees of freedom are available, $k$, is determined using the appropriate degrees of freedom and the $95.45 \%$ column in the table from Appendix A of NISTIR 6969, SOP 29.

\section{Certificate}

Report results as described in SOP No. 1, Preparation of Calibration Certificates. Report the Conventional Mass, environmental conditions during the calibrations, and calculated 
uncertainties. No correction for the effect of air buoyancy is to be assumed unless stated on the calibration certificate. In addition to requirements of SOP 1, the following information is included on the calibration certificate:

- Master Scale identity and its calibration date;

- Railroad test car identification;

- Stenciled conventional mass value;

- "As found" mass value (with explanation of adjustments, if appropriate);

- "As left" mass value (railroad test cars that have demonstrated excessive wear from year to year may be left on the higher side of the tolerance to compensate for wear); and

- Signature of witnesses to the calibration, if appropriate and desired. 


\section{Appendix A - Types of Railroad Test Cars}

6.1 Monitor car. Essentially a modified freight car with approved lading to which field calibration has been performed. These cars cannot be verified on a railroad master scale. They are used only in emergency situations such as returning a scale to service pending the arrival of a certified test car.

6.2 Composite car. Each composite car is provided by design with a tool and/or cargo compartment, usually runs transversely through the car body which can be secured by lock or wire seal. Wheel base lengths (center of front axle to center of rear axle) shall not exceed $7 \mathrm{ft}$. Composite cars are calibrated on railroad track master scales. Standard composite car values range from $30000 \mathrm{lb}$ to $110000 \mathrm{lb}$ in multiples of $10000 \mathrm{lb}$.

6.3 Self-contained car. The self-contained type of test weight car has a metal body made up of either one or two castings mounted on a $7 \mathrm{ft}$ wheel base with a space provided to contain a small number of $50 \mathrm{lb}$ or smaller test weights. This compartment is called the adjustment cavity and is secured by lock or seal.

6.4 Compartment car. The compartment car is constructed of one or more casting or fabricated steel plates mounted on a $7 \mathrm{ft}$ wheel base forming a shell that can be loaded with $50 \mathrm{lb}$ or $100 \mathrm{lb}$ weights to a value at least equal to the weight of the empty car. The compartment is secured by lock or seal.

6.5 Long wheel base car. The self-propelled hydraulic jack design is of average freight car length and employs four hydraulic jacks spaced $7 \mathrm{ft}$ apart (to simulate a $7 \mathrm{ft}$ wheel base for section testing) which are lowered to the scale section which is to be tested (repeated per number of sections). The self-propelled design allows the car to move autonomously onto the scale.

Material for this SOP was collected and reviewed between 1998 and 2018 with input from Bruce Adams, MN, Vic Gerber, WY, Marcus Harwitz, U.S. Department of Agriculture, R.C. Holmes, Union Pacific Railroad, F.J. Loyd, Jr., CSX Railroad, Gerald E. Davis, Conrail, Paul Hadyka, USDA-GIPSA, Bill Norrs, USDA-GIPSA, W.G. GeMeiner, Union Pacific Railroad, John Robinson, Association of American Railroads, Association of American Railroads Scale Handbook and GIPSA Weighing Handbook, Chapter 3, Railroad Track Scales. 
SOP 49

\section{Standard Operating Procedure}

for

\section{Calibration of Environmental Monitoring Standards by Direct Comparison}

1 Introduction

\section{$1.1 \quad$ Purpose}

The purpose of this procedure is to use calibrated environmental sensors/instruments as short-term transfer standards immediately after its calibration to perform downstream calibration of internal laboratory environmental sensors/instruments for calibration, verification that measurement results continue to be stable, or for validation of extending calibration intervals. The procedure may be suitable for sensors/instruments that are used for laboratory monitoring where a larger uncertainty may be acceptable and possibly for other calibration uses provided the application and required uncertainties are evaluated and found to be acceptable.

\subsection{Range and Scope}

Detailed measurement ranges, standards, equipment, and uncertainties for this SOP are generally compiled in a separate document in the laboratory (e.g., traceability hierarchy, uncertainty tables). Uncertainties of this process must be assessed (Section 5.5) to determine if they are sufficiently small for the standards to be used in downstream calibrations or if uncertainties are only suitable for laboratory monitoring applications.

\subsection{Limitations}

The temperature range is limited from $15^{\circ} \mathrm{C}$ to $25^{\circ} \mathrm{C}$ if based on typical laboratory conditions; the range in air may be from $5^{\circ} \mathrm{C}$ to $95^{\circ} \mathrm{C}$ if a wider range of calibrated standards and whether an oven, temperature bath, or ability to vary conditions are available/possible. Barometers are compared under various laboratory ambient pressures. Relative humidity is compared over during several days with various ambient laboratory humidity conditions unless a humidity chamber is available or the laboratory can vary conditions.

If multiple points are obtained during varying conditions observed in the comparisons, such as through use of a temperature bath/oven or use of relative humidity salt solutions, only the range of measurements between multiple calibration points may be considered suitable for calibration applications, provided the uncertainty is sufficiently small. If the prior calibration(s) of the instrument being calibrated demonstrated a best fit linear response where all offsets from nominal were within the stated uncertainty, a one-point calibration may be used. When a one-point calibration is used, such as at standard 
environmental conditions only, the instrument should only be used for environmental monitoring and should also be verified again at one-fourth of the intended calibration interval to ensure ongoing accuracy and stability under laboratory environmental conditions.

\subsection{Prerequisites}

1.4.1 Staff must have suitable training and have demonstrated proficiency in comparison calibration measurements, e.g., those used in temperature, mass, volume, and dimensional parameters.

1.4.2 Valid calibration certificates that are less than 30 days old, with appropriate values and uncertainties, must be available for all the standards used in this calibration. All standards must have demonstrated metrological traceability to the international system of units (SI), which may be to the SI through a National Metrology Institute such as NIST. Exception: where the calibration of the standards is not less than 30 days old, enough laboratory data must be available to demonstrate historical stability of the instrument to the limits needed for this calibration.

1.4.3 Standards must be evaluated to ensure that standard uncertainties for the intended level of calibration are sufficiently small. The uncertainties resulting from this procedure may be suitable for monitoring laboratory conditions but not suitable for use in calibration processes unless the uncertainties of the standard calibration and the resolution of the standard are sufficiently small (i.e., the uncertainty of the instruments used as a standard must have better resolution than the instruments being calibrated if they are to be used as downstream measurements for calibrations).

1.4.4 Maintain environmental conditions within the limits noted in Table 1. These limits are not critical for this calibration; the limits are recommended based on good laboratory environmental control practices.

Table 1. Suggested Environmental limits for calibrations.

\begin{tabular}{|c|c|c|c|}
\hline $\begin{array}{c}\text { Temperature } \\
\text { Range }\end{array}$ & $\begin{array}{c}\text { Temperature } \\
\text { Stability }\end{array}$ & Relative Humidity & $\begin{array}{c}\text { Relative Humidity } \\
\text { Stability }\end{array}$ \\
\hline \hline $18{ }^{\circ} \mathrm{C}$ to $23^{\circ} \mathrm{C}$ & $\pm 1^{\circ} \mathrm{C}$ & $40 \%$ to $60 \%$ & $\pm 2 \%$ \\
\hline
\end{tabular}

$2 \quad$ Methodology

\subsection{Summary}

Laboratory environmental sensors/instruments are used as transfer standards to calibrate internal environmental sensors/instruments owned by the laboratory 
using direct comparison procedures over a series of days. Results are used to provide for calibration, evaluation of the calibration status, or stability of measurement results to support calibration intervals.

\subsection{Equipment / Apparatus}

Limits given in this section are used to evaluate the final calibration results from this procedure when sensors/instruments will be used to provide corrections in subsequent calibrations (e.g., buoyancy corrections in mass or gravimetric volume calibrations; air density corrections used in dimensional calibrations). In this case, the calibrated uncertainty limits of the sensors/instruments to be used as standards must be significantly smaller than limits stated in this section (e.g., by enough so that conformity statements to these limits may be made based on measurement results and calculated uncertainties). See NISTIR 6969, SOP 2 for recommended limits for calculating air density.

When the following limits are not attainable, the final measurement results and uncertainties may be evaluated for suitability for use as laboratory monitoring sensors/instruments. Monitoring limits might consider $1 \%$ of the air density limits as shown in SOP 2.

2.2.1 Calibrated barometer with sufficiently small resolution, stability, and uncertainty (See NISTIR $6969^{1}$, SOP 2, e.g., accurate to $\pm 66.5 \mathrm{~Pa}(0.5$ $\mathrm{mm} \mathrm{Hg))} \mathrm{to} \mathrm{determine} \mathrm{barometric} \mathrm{pressure.}{ }^{1}$

2.2.2 Calibrated thermometer with sufficiently small resolution, stability, and uncertainty (see SOP 2, e.g., accurate to $\pm 0.10{ }^{\circ} \mathrm{C}$ ) to determine air temperature. ${ }^{1}$

2.2.3 Calibrated hygrometer with sufficiently small resolution, stability, and uncertainty (see SOP 2, e.g., accurate to \pm 10 percent) to determine relative humidity. ${ }^{1}$

\subsection{Procedure}

2.3.1 Identify a sensor/instrument that was recently calibrated by an accredited supplier and where the calibration certificate has been evaluated to ensure suitable measurement results and uncertainties are available. Verify that the standard and any constants from calibration reports have been entered into their respective devices correctly (if applicable). This instrument will be used as the standard, $S$, for this comparison procedure.

${ }^{1}$ NISTIR 6969, Selected Laboratory and Measurement Practices, and Procedures to Support Basic Mass Calibrations. SOP 2, Applying Air Buoyancy Corrections. 
2.3.2 Equilibrate the standard and the instrument to be calibrated, $X$, for 2 hours to 4 hours in a suitable laboratory environment. If the instruments have been outside of a laboratory environment, allow a 24 hour equilibration time.

2.3.2.1 Electronic equipment should be plugged in and warmed up as specified in their operating manuals.

2.3.2.2 Ensure that all barometers are at the same elevation and that station pressure values are used (not sea-level pressures).

2.3.2.3 All thermometers involved in the calibration should be placed in a stable medium (determined by sensor type). If a temperature oven or bath is available, it is preferred. However, a solid block or closed air system may be used for probes restricted to air; immersed block in water that is equilibrated to laboratory conditions may be used for liquid-compatible probes.

2.3.3 Option A. Obtain and record observed measurement values for the Standard, S, and Unknown, X, for temperature $S_{t}, X_{t}$, for pressure, $S_{P}$, $X_{P}$, and for relative humidity $S_{R H}, X_{R H}$, as shown on the Appendix A data sheet for Option A. Record observations over a period of three days, taking care to record or convert to similar measurement units. Record the measurements of each parameter within $30 \mathrm{~s}$ of each other to minimize potential drift due to laboratory environment or human influence factors in the measurement results. If additional degrees of freedom are needed, for example, where pooled standard deviations are not available, this process may be extended over more days. (Do not perform all three sets of observations on the same day).

2.3.4 Option B. If excess drift is suspected or observed in either the instruments or the environment, use two sets of observations in reverse order $\left(S_{1}, X_{1}, X_{2}, S_{2}\right)$ on each day (double substitution) for temperature, pressure, and relative humidity. Record data as shown on the Appendix A data sheet for Option B. Calculations (Measurement Equations)

Perform the following calculations for each measurement parameter that is being calibrated (temperature, pressure, relative humidity) as applicable. 
3.1 Calculate the three observed measurement differences, $d_{n}$, for each of the measurement parameters spread out over three different days:

3.1.1 To calculate the observed difference for Option A, use Eqn. 1 for temperature, pressure, and relative humidity observations (obs).

$$
d_{n}=X_{o b s}-S_{o b s}
$$

3.1.2 To calculate the observed difference for Option B, use Eqn. 2 for temperature, pressure, and relative humidity observations as numbered.

$$
d_{n}=\frac{X_{1}-S_{1}+X_{2}-S_{2}}{2}
$$

3.2 Calculate the mean value for the observed measured differences, $\bar{d}$.

3.3 Calculate the correction for each instrument parameter (temperature, barometric pressure, relative humidity as applicable), $C_{x}$, using the correction for the reference standard, $C_{s}$, taking care to ensure the correct sign and reference value is used. Note: some corrections, especially in thermometry, are not additive to the nominal value.

$$
C_{x}=C_{s}+\bar{d}
$$

Measurement Assurance

4.1 Three replicate comparisons are performed during the measurement process to calculate a replicate standard deviation.

4.2 Replicate standard deviations are tracked on a standard deviation chart for this process and the replicate process standards deviation are pooled over time. Calibration repeatability is evaluated against the limits on the chart and assessed based on the limits of uncertainty needed for subsequent calibration and use in the laboratory. Where repeatability and final uncertainties are too large, a better calibration method or calibration source are essential.

4.3 Where a check standard instrument is available, values for that instrument may be tracked over time. However, if instruments are not identical in type and resolution, the variability of a check standard may not be a suitable duplication for an unknown standard to use the standard deviation of the check standard for the process repeatability. The value of the check standard may provide a suitable check on the stability of measurement results over time. 
5.1 Uncertainty for the standard, $u_{s}$.

The uncertainty for the standard is obtained from the calibration certificate for the reference standard that is used for this calibration. Determine the degrees of freedom for the standard by reviewing the calibration certificate. If a coverage factor of 2 is stated, an estimate of 500 degrees of freedom may be used for the standard (this is an estimated value and other reasonable estimates may be used).

5.2 Uncertainty for the process, $s_{p}$.

The uncertainty for the standard deviation of the process is obtained from the replicate standard deviation.

Since the degrees of freedom are very small for this calibration (2), a higher coverage factor may be needed (See Appendix A in NISTIR 6969, SOP 29). A greater number of replicate observations may be obtained for an equal number of days, e.g., 7 observations obtained over 7 days, or 10 observations obtained over 10 days to increase the degrees of freedom for this component.

Use a pooled replicate standard deviation where possible. A pooled value of the replicate standard deviation will provide greater degrees of freedom to be used for calculating the coverage factor for the uncertainty.

Where the standard deviation is less than the resolution of the instrument, use an uncertainty for the process, $u_{p}$, of the larger of either the calculated standard deviation, $s_{p}$, or the value calculated from the following formula. The laboratory may also round up to the nearest resolution of the instrument.

$$
u_{p}=\frac{\text { resolution }}{\sqrt{3}}
$$

5.3 Uncertainty for other components, $u_{o}$.

Where instrument history or stability information are available, additional components should be considered in the evaluation of the uncertainty. The estimate of drift during a calibration interval may be treated as a rectangular distribution. While this will increase the uncertainty, it will provide a more realistic assessment of uncertainty to be used when evaluating the suitability of this procedure. 
Table 2. Example Uncertainty Budget Table.

\begin{tabular}{||l|c|c|c||}
\hline \multicolumn{1}{|c|}{$\begin{array}{c}\text { Uncertainty Component } \\
\text { Description }\end{array}$} & Symbol & Source & $\begin{array}{c}\text { Typical } \\
\text { Distribution }\end{array}$ \\
\hline \hline $\begin{array}{l}\text { Uncertainty of the standard } \\
\text { used as a reference } \\
\text { temperature, pressure, relative } \\
\text { humidity) }\end{array}$ & $u_{s}$ & Calibration certificate & $\begin{array}{c}\text { Expanded } \\
\text { divided by the } \\
\text { coverage } \\
\text { factor, } k\end{array}$ \\
\hline $\begin{array}{l}\text { Standard deviation from } \\
\text { replicate measurements }\end{array}$ & $s_{p}$ & $\begin{array}{c}\text { Standard deviation from replicate } \\
\text { measurements, } \\
\text { Pooled standard deviation where data } \\
\text { is available from similar instruments }\end{array}$ & Normal \\
\hline $\begin{array}{l}\text { Standard deviation from } \\
\text { replicate measurements - when } \\
\text { standard deviation is less than } \\
\text { resolution }\end{array}$ & $u_{p}$ & $\begin{array}{c}\text { Estimated process uncertainty based } \\
\text { on resolution of the instrument being } \\
\text { calibrated }\end{array}$ & $\begin{array}{c}\text { Rectangular or } \\
\text { rounded up to } \\
\text { nearest } \\
\text { resolution }\end{array}$ \\
\hline Estimates of drift & $u_{o}$ & $\begin{array}{c}\text { Historical evaluation of stability in the } \\
\text { instruments (where available) }\end{array}$ & Rectangular \\
\hline
\end{tabular}

5.4 Calculate the combined and expanded uncertainty following the procedure in NISTIR 6969, SOP 29. Use appropriate effective degrees of freedom using the Welch-Satterthwaite equation as noted in NISTIR 6969, Section 8 or from the Guide to the Expression of Uncertainty in Measurement.

5.5 Evaluate the expanded uncertainty.

Determine whether the measurement results and uncertainties will meet requirements for corrections needed for calibrations (e.g., per SOP 2), for monitoring laboratory conditions, or for other intended application and use.

\section{Certificate}

Report results according to SOP 1, ISO/IEC 17025, and applicable customer requirements. Report the mean values of the temperature, pressure, relative humidity (as appropriate). Include the range of environmental conditions observed during the calibrations and report the estimated calculated uncertainties. Report the reference calibration certificate and date for the instrument used as the standard. Include a suitability statement to the effect of whether the calibration may be used for calibration corrections and/or for monitoring laboratory environmental conditions.

Note: If this is an internal calibration and/or not covered by the scope of accreditation or recognition, follow accreditation body requirements regarding any additional statements that may be required when such measurements are not covered by the Scope. 


\section{Appendix A - Data Sheet}

Laboratory data and conditions:

\begin{tabular}{|c|c|c|c|}
\hline Operator & Laboratory Conditions & Before & After \\
\hline Date Range & Temperature & & \\
\hline $\begin{array}{r}\text { Replicate standard deviation of the } \\
\text { process, from standard deviation } \\
\text { chart, } s_{p}\end{array}$ & Pressure & & \\
\hline Degrees of Freedom & Relative Humidity & & \\
\hline
\end{tabular}

Standard(s) data:

\begin{tabular}{|c|c|c|c|c|c|c|}
\hline ID & Nominal $^{\mathrm{a}}$ & Correction $^{\mathrm{b}}$ & $\begin{array}{l}\text { Measurement } \\
\text { Units }\end{array}$ & $\begin{array}{l}\text { Expanded Unc: } \\
\text { From cal. } \\
\text { certificate } \\
\end{array}$ & $\begin{array}{l}\text { Unc. } \\
k \text { factor }\end{array}$ & Unc. Units \\
\hline \multicolumn{7}{|l|}{$S$ - temperature } \\
\hline \multicolumn{7}{|l|}{$S$ - pressure } \\
\hline \multicolumn{7}{|l|}{$S$ - relative humidity } \\
\hline \multicolumn{7}{|c|}{$\begin{array}{l}\mathrm{a} \text { selected reference value from the calibration certificate nearest to normal laboratory conditions. } \\
\text { b taking care to determine directionality as appropriate }\end{array}$} \\
\hline \multicolumn{7}{|c|}{ Identification of the standards, serial number: } \\
\hline \multicolumn{7}{|c|}{ Identification of the standards, calibration source: } \\
\hline
\end{tabular}

Measurement Observations, Option A (Record Units in Column Headings):

\begin{tabular}{|r|l|l|l|l|l|l||}
\hline \hline \multicolumn{1}{|r|}{ Dates } & $S_{t}$ & $X_{t}$ & $S_{P}$ & $X_{P}-$ & $S_{R H}$ & $X_{R H}-$ \\
\hline \hline 1 & & & & & & \\
\hline 2 & & & & & & \\
\hline 3
\end{tabular}

Measurement Observations, Option B (Record Units in Column Headings):

\begin{tabular}{|c|c|c|c|c|c|c|c|c|c|c|c|c|}
\hline & \multicolumn{4}{|c|}{ Temperature } & \multicolumn{4}{|c|}{ Pressure } & \multicolumn{4}{|c|}{ Relative Humidity } \\
\hline Dates & $S_{1}$ & $X_{1}$ & $X_{2}$ & $S_{2}$ & $S_{1}$ & $X_{1}$ & $X_{2}$ & $S_{2}$ & $S_{1}$ & $X_{1}$ & $X_{2}$ & $S_{2}$ \\
\hline 1 & & & & & & & & & & & & \\
\hline 2 & & & & & & & & & & & & \\
\hline 3 & & & & & & & & & & & & \\
\hline
\end{tabular}




\section{SOP 52}

\section{Standard Operating Procedure \\ for}

\section{Verification and Adjustment of Digital Conductivity Meter and Measuring Water Conductivity}

1 Introduction

1.1 Purpose. This specification covers the procedure for testing the conductivity and resistivity of the water stored and used in the laboratory for gravimetric calibrations. This specification also covers the procedure for adjustment of a digital conductivity meter used for conductivity and resistivity testing. The conductivity meter may have a probe to dip into the water or may have an integrated cell to receive the sample. Note: conductivity is a relative indicator of purity and is not specific for density measurements of water. An in-line conductivity sensor with a suitable probe may be evaluated with this procedure with appropriate modifications.

1.2 Applicable References:

1.2.1 Good Laboratory Practice (GLP) 10, Purity of Water.

1.2.2 Operation manual and instructions for conductivity meter.

1.3 Prerequisites

1.3.1 Ensure staff have suitable on-the-job training and have demonstrated proficiency with this procedure.

1.3.2 Standard Reference Material (SRM) or Certified Reference Material (CRM) for conductivity or resistivity reference measurements that have suitable calibration or test certificates and that solutions are up to date (have not expired).

1.3.3 Adequate supply of distilled, deionized, or reverse-osmosis/deionized water per GLP 10.

1.3.4 Maintain environmental conditions within the limits noted in Table 1.

Table 1. Environmental limits for calibrations (as used for Gravimetric Volume Calibrations).

\begin{tabular}{|c|c|}
\hline Temperature & Relative Humidity \\
\hline \hline $18{ }^{\circ} \mathrm{C}$ to $23^{\circ} \mathrm{C}$ & $40 \%$ to $60 \%$ \\
Stable to $\pm 1{ }^{\circ} \mathrm{C} / 1 \mathrm{~h}$ & Stable to $\pm 10 \% / 4 \mathrm{~h}$ \\
\hline \hline
\end{tabular}




\section{$2.1 \quad$ Summary}

This procedure is used as a verification step for water quality indications as a part of gravimetric volume calibrations. The procedure includes testing the digital conductivity meter, applicable adjustments based on standard/certified reference materials, and use of the conductivity meter to verify acceptable water quality per GLP 10 .

\subsection{Equipment / Apparatus}

2.2.1 Conductivity/Resistivity meter. Conductivity units ${ }^{1}$ are siemens, symbol S, usually represented as $\mathrm{mS} / \mathrm{cm}$ or $\mu \mathrm{S} / \mathrm{cm}$. Resistivity is usually in Ohm-cm units, such as $\mathrm{M} \Omega-\mathrm{cm}$ or $\mu \Omega$-cm, with ohms represented by $\Omega$. The values are reciprocals of each other, $\mathrm{S}=\Omega^{-1}$.

2.2.2 Calibrated thermometer with resolution and uncertainty less than $0.1^{\circ} \mathrm{C}$ to determine liquid temperatures.

2.2.3 Appropriately sized beakers or flasks for pure water (distilled, deionized). E.g., $1000 \mathrm{~mL}, 100 \mathrm{~mL}$.

2.2.4 Small tools for adjusting conductivity meter (e.g., flat head screw driver).

2.3 Procedure for Conductivity Meter with Probe, Verification and Adjustment

2.3.1 Turn on the water system in the volume laboratory.

2.3.2 Retrieve the conductivity meter, a $100 \mathrm{~mL}$ glass flask, and an up to date SRM/CRM.

2.3.3 Connect the conductivity meter probe to the meter.

2.3.4 Rinse the $100 \mathrm{~mL}$ flask with pure water. Open the water system valve and let the water run for approximately 5 to 10 seconds. Rinse the 100 mL flask several times.

2.3.5 Pour approximately $30 \mathrm{~mL}$ of SRM/CRM into the $100 \mathrm{~mL}$ flask. Dip the probe into the flask so that the SRM/CRM covers the probe and then remove the probe from the flask (this is to coat and condition the probe and sensors). Rinse the probe in the SRM/CRM.

\footnotetext{
${ }^{1}$ The SI unit of conductivity is siemens per meter (S/m). The 14th General Conference on Weights and Measures approved the addition of the siemens as a derived unit in 1971. In the case of direct current (DC), conductance units in siemens is the reciprocal of the resistance in ohms ( $\mathrm{S}$ = amperes per volts); in the case of alternating current (AC), it is the reciprocal of the impedance in ohms. A former term for the reciprocal of the ohm is the mho (ohm spelled backward).
} 
2.3.6 Rinse the $100 \mathrm{~mL}$ flask with the SRM/CRM. Cover with a suitable lid/thumb and shake the flask so the SRM/CRM coats the inside of the flask.

2.3.7 Pour the SRM/CRM in the flask into the sink.

2.3.8 Take note of the Conductivity Reference value in $\mu \Omega$-cm from the certificate or original container to use later.

2.3.9 Pour approximately $30 \mathrm{~mL}$ of the SRM/CRM into the $100 \mathrm{~mL}$ flask. Dip the probe into the flask so that the Conductivity Standard covers the probe.

2.3.10 Push the conductivity meter switch to the $0.1 \mu \Omega$ to $199.9 \mu \Omega$ position. Check the conductivity meter reading against the value obtained in step 2.3.8.

2.3.11 Adjust the conductivity meter if possible and needed. This may be done by turning a small screw on the conductivity meter, using a suitable tool, until the value on the conductivity meter matches the value obtained in step 2.3.8.

2.3.12 Remove the probe and place back into the solution several times verifying that the reading on the conductivity meter matches the value obtained in step 2.3.8. If it does not then repeat step 2.3.11.

2.3.13 When the readings are repeatable the meter is ready for use to evaluate water quality.

2.3.14 When finished, turn off the conductivity meter. Empty the $100 \mathrm{~mL}$ flask and rinse with pure water. Dry the flask. Use extreme care to dry the conductivity meter probe by gently dabbing with a paper towel. Remove the probe from the conductivity meter.

2.3.15 Turn off the pump for the water system and put all items away.

2.3.16 Make a note in the Control Chart in the "Notes" column that the reference was set and which reference standard material was used. Record this information with the Gravimetric Calibration data sheet as well.

2.4 Procedure for Verification of Conductivity Meter with Integrated Conductivity Cell

2.4.1 Turn on the water system in the volume laboratory.

2.4.2 Retrieve the conductivity meter, a small glass flask, and an up to date Conductivity Reference Standard. 
2.4.3 Rinse the small flask with pure water. Open the water system valve and let the water run for approximately 5 to 10 seconds. Rinse the flask several times.

2.4.4 Fill the receiving cell of the conductivity meter with the SRM/CRM and rinse. Repeat at least two more times, using the last fill as the reference reading. This conditions the temperature sensing network and prepares the cell.

2.4.5 Pour the SRM/CRM from the meter into the sink.

2.4.6 Take note of the Conductivity Reference value in $\mu \Omega$-cm from the certificate or original container for comparison with 2.4.4. Record observations from the conductivity meter and the SRM/CRM and note any differences.

2.4.7 Adjust the conductivity meter with the SRM/CRM in the cell if the meter has an adjustment feature following the manufacturer's instructions (often using a "Cal" button to adjust the integrated electronic sensor readings).

2.4.8 When the readings are repeatable the meter is ready for use to evaluate water quality.

2.4.9 When finished, turn off the conductivity meter and rinse several times with pure water. Empty flasks and rinse with pure water. Dry the flasks. Do not scrub the integrated cell or sensors.

2.4.10 Turn off the pump for the water system and put all items away.

2.4.11 Make a note in the Control Chart in the "Notes" column that the reference was set and which reference standard material was used. Record this information with the Gravimetric Calibration data sheet as well.

2.5 Procedure for Water Quality Evaluation, Using a Meter with a Probe

2.5.1 Turn on the water system in the volume laboratory.

2.5.2 Obtain the conductivity meter, the $1000 \mathrm{~mL}$ flask, and the thermometer.

2.5.3 Connect the conductivity meter probe to the meter (unless integrated in the unit) and turn on the unit.

2.5.4 Push the conductivity meter switch to the $2.00 \mathrm{M} \Omega$ to $19.99 \mathrm{M} \Omega$ position. The meter should read 1 . 
2.5.5 Push the conductivity meter switch to the $0.1 \mathrm{M} \Omega$ to $199.9 \mathrm{M} \Omega$ position. The meter should read 0.00 .

2.5.6 Rinse the $1000 \mathrm{~mL}$ flask. Open the pure water system valve and let it run for approximately 5 to 10 seconds, rinse out the $1000 \mathrm{~mL}$ flask several times and then fill it to approximately $1000 \mathrm{~mL}$. Turn off the water.

2.5.7 Place the probe from the conductivity meter into the $1000 \mathrm{~mL}$ flask.

2.5.8 Push the conductivity meter switch to the $0.1 \mathrm{M} \Omega$ to $199.9 \mathrm{M} \Omega$ position and record the value on the observation sheet for the calibration. Monitor water quality on a control chart as well.

2.5.9 Push the conductivity meter switch to the $2.00 \mathrm{M} \Omega$ to $19.99 \mathrm{M} \Omega$ position and record the value on the observation sheet for the calibration. Monitor water quality on a control chart as well.

2.5.10 Take the temperature of the water that was just tested using the digital thermometer and record it on the observation sheet and the control chart data sheet.

2.5.11 Enter the observations readings into the appropriate control chart.

2.5.12 Empty the flask and dry it off with a paper towel. Dry off the thermometer probe. Use extreme care to dry the conductivity meter probe by gently dabbing with a paper towel. Disconnect the probe from the conductivity meter.

2.5.13 Turn off the water system (if calibration is complete) and put all items away.

2.6 Procedure for Water Quality Evaluation, Using a Meter with Integrated Conductivity Cell

2.6.1 Turn on the water system in the volume laboratory.

2.6.2 Obtain the conductivity meter, a $1000 \mathrm{~mL}$ flask, and the thermometer.

2.6.3 Rinse the $1000 \mathrm{~mL}$ flask. Open the pure water system valve and let it run for approximately 5 to 10 seconds, rinse out the $1000 \mathrm{~mL}$ flask several times and then fill it to approximately $1000 \mathrm{~mL}$. Turn off the water.

2.6.4 Place a sample in the conductivity meter from the flask.

2.6.5 Record the value of the conductivity meter on the observation sheet for the calibration. Monitor the water quality on a control chart as well. 
2.6.6 Take the temperature of the water that was just tested using the digital thermometer and record it on the observation sheet and the control chart data sheet.

2.6.7 Enter the observations readings into the appropriate control chart.

2.6.8 Empty and dry the flask and thermometer probe.

2.6.9 Turn off the water system (if calibration is complete) and put all items away.

3 Calculations (Measurement Equations)

There are no calculations in this SOP. See GLP 10 for calculations of water density.

4

Measurement Assurance

This procedure is part of the measurement assurance required for GLP 10, Water Purity evaluation and SOP 14, Gravimetric Volume Calibrations to ensure suitable water quality for use in calibrations.

Monitor laboratory water quality over time on a control chart if desired. This will help track maintenance or service requirements for the water purification system.

\section{Assignment of Uncertainty}

No uncertainties are assigned for this procedure.

$6 \quad$ Certificate

Documentation of conductivity meter evaluation and water quality assessments are included with the recorded measurement data for volume calibrations as appropriate. No calibration or test certificates are issued. Temperature of the water at the time of verification and the relevant information from the SRM/CRM should be recorded as well (e.g., brand, serial or sample number, certificate reference, date of test/certification, and status of the laboratory providing conductivity certification).

7 Acknowledgements and Validation

The original SOP for this procedure was submitted by the State of Pennsylvania and modified by Georgia Harris to make the procedure generic, incorporate the SRM/CRM terminology, to incorporate a conductivity/resistivity meter with integrated sensor/cell that is in use within OWM, and to review the instruction manuals for the meters referenced in this SOP. 